\title{
Use of morphological characteristics to define functional groups of predatory fishes in the Celtic Sea
}

\author{
Y. Reecht ${ }^{1, \text { a }}$, M.-J. Rochet ${ }^{1,{ }^{*}}$, V. M. Trenkel ${ }^{1}$, S. Jennings ${ }^{2}$, J. K. Pinnegar ${ }^{2}$ \\ ${ }^{1}$ IFREMER, Rue de l'Ile d'Yeu, B.P. 21105, 44311 NANTES Cedex 03, France \\ 2 Centre for Environment, Fisheries and Aquaculture Science, Lowestoft Fisheries Laboratory, Lowestoft NR33 \\ OHT, U.K \\ ${ }^{\text {a }}$ Present address : Ifremer, RHBL, 150 quai Gambetta, 62200 Boulogne-sur-Mer, France. \\ *: Corresponding author : Marie-Joëlle Rochet, Tel.: +33 2403741 21; email: Marie.Joelle.Rochet@ifremer.fr
}

\begin{abstract}
:
An ecomorphological method was developed, with a focus on predation functions, to define functional groups in the Celtic Sea fish community. Eleven functional traits, measured for 930 individuals from 33 species, led to 11 functional groups. Membership of functional groups was linked to body size and taxonomy. For seven species, there were ontogenetic changes in group membership. When diet composition, expressed as the proportions of different prey types recorded in stomachs, was compared among functional groups, morphology-based predictions accounted for $28-56 \%$ of the interindividual variance in prey type. This was larger than the $12-24 \%$ of variance that could be explained solely on the basis of body size.
\end{abstract}

Keywords: ecomorphology ; functional traits ; predation strategy ; trophic functions 


\section{Introduction}

An understanding of predator-prey interactions is needed to predict the behaviour of marine food webs and their responses to human impacts. Classification of individuals and/or species into functional groups may help simplify some types of food web models and reduce parameter demands. Functional groups can therefore be useful tools to understand (Mouillot et al., 2006), monitor and manage marine communities (Auster \& Link, 2009). Typically, food webs are constructed by grouping species and/or size ranges into functional groups, based on diet data (e.g. Garrison \& Link, 2000b; Mackinson et al., 2009). However, diet data are expensive to collect and diet varies in space and time with prey availability (e.g. Pinnegar et al., 2003; Trenkel et al., 2005; Bacha \& Amara, 2009; Binning \& Chapman, 2010). Diet-based approaches for grouping species into functional groups might usefully be complemented by other methods. For example, both species identity (e.g. Dumay et al., 2004; Heath, 2005; Albouy et al., 2011) and size (Jennings et al., 2002; De Roos et al., 2003; Shin et al., 2005) are expected to influence prey choice and functional role. Few studies have investigated the effects of both size and taxonomy on the functional role of predators in communities (but see Garrison \& Link, 2000a; Garrison \& Link, 2000b; Inoue et al., 2005).

Effect functions, hereafter referred to as 'functions', describe how an entity affects its environment (Naeem \& Wright, 2003; Jax, 2005). The ecomorphological approach provides a useful framework for investigating the contribution of size and species identity to function (see review by Sibbing \& Nagelkerke, 2001). For instance, the traits that constrain the range of prey that a predator can catch, handle and digest will determine the impact of this predator on the ecosystem (i.e. its predation effect function). A number of studies have provided evidence of relationships between morphology and function (e.g. Hjelm et al., 2001; Hjelm et al., 2003; Carroll et al., 2004).

A range of functional traits are known to be related to diet. For example, fishes with long relative gut length characteristically feed on energetically poor food that is hard to digest (i.e. algae, detritus), while fishes with short guts tend to be carnivorous and feed on energy and protein rich prey (Piet, 1998; Xie et al., 2001; Boyle \& Horn, 2006; Ibañez et al., 2007; Karachle \& Stergiou, 2010) and fishes with larger gape size tend to handle a wider range of prey sizes and may feed on larger prey (Luczkovich et al., 1995; Persson et al., 1996; Labropoulou \& Eleftheriou, 1997; Lima-Junior \& Goitein, 2003).

A method is proposed to define functional groups in a fish community, focusing on predation functions in Celtic Sea fishes and using an ecomorphological approach. The approach uses morphological measurements to predict those characteristics, dubbed 'subfunctions', that contribute to the predation function. The sub-functions are: (1) swimming capacity that is related to pursuit ability and energy needs (2) type of approach to capture prey and (3) capacity to eat and digest given sizes and types of prey if they are encountered. The classifications obtained with these sub-functions are then combined to define functional groups. Next it is assessed whether the classification is driven by size, taxonomy, or both. The suitability of a functional group-based classification for predicting differences in diet composition is compared with an approach based solely on body size. 


\subsection{Biological material}

Data from the French EVHOE ground-fish survey for the period 1997-2005 (Trenkel et al., 2004) were used to identify the most abundant species in the Celtic Sea fish community. This survey covers the Celtic Sea continental shelf (bounded to the North by Ireland, to the North-East by the UK, to the East by the English Channel and to the South-East by Brittany, i.e. the majority of ICES statistical areas VIIf to $\mathrm{h}$ and $\mathrm{j}$ ) in November and December every year. It is stratified by depth (seven depth bands as described in survey protocol: http://datras.ices.dk/Documents/Manuals/EVHOEManual.doc; last accessed 15 March 2013) and by area (South, North-East and North-West of the total survey area). Catch weight by species and species' length distributions $(\mathrm{cm})$ were recorded following each of the randomly distributed 30 minutes tows. The survey data were used to describe species occurrence (proportion of hauls containing a given species) and species densities (raised abundance and biomass over strata as individuals $\mathrm{km}^{-2}$ and $\mathrm{kg} \cdot \mathrm{km}^{-2}$ with no catchability correction applied). Among species with occurrence $>10 \%$, those (1) with densities $>50$ individuals $\cdot \mathrm{km}^{-2}$ or $>9 \mathrm{~kg} \cdot \mathrm{km}^{-2}$ or (2) that collectively contributed to $80 \%$ of biomass in at least one stratum when ranked by biomass, were selected. Thirty three fish species (see Table SI in online supporting material) were selected based on these criteria. These species accounted for over $96 \%$ of the overall biomass in the surveyed fish community from 1997 to 2005 inclusive.

Individuals of the 33 selected species were sampled from 2006 EVHOE survey catches in the Celtic Sea for morphological measurements. For each species, the target sample size was 30 individuals, from evenly spaced length classes spanning the range of lengths that were caught. The largest individuals and/or species were measured on board while smaller ones were frozen and subsequently measured in the laboratory.

Diet was described for the selected species using stomach content data recorded in the Celtic Sea between 1977 and 1994 and compiled by Pinnegar et al. (2003). Stomach contents were expressed as the number of prey items classified into 145 prey types, identified at the highest level of taxonomic resolution possible. Diet data were available for 31 of the 33 selected species. Data for Greater-argentine Argentina silus (Ascanius 1775) and Spotted-dragonet Callionymus maculatus (Rafinesque 1810) were not available and these species were not included in the diet analyses.

\subsection{Functional trait measurements}

The selection of functional traits to be used in the analysis was based on published literature that linked form and function. Eleven functional traits were calculated (Table I) and the measurements taken to calculate these traits are described in Fig. 1. Total (or standard) length was not treated as a functional trait since mass and mouth gape were deemed to be more closely related to function. Total length was used (Lt; Fig. 1) to assign fish to size categories for analysis.

To measure fin dimensions and areas, each fish was photographed with the caudal fin widely spread. The span and area of fins were measured using ImageJ (version 1.38X, 
Rasband, 1997-2007). Measurements in pixels (Ac and Sc, Fig. 1) did not need to be converted to SI units because they were only used to assess the dimensionless caudal fin aspect ratio.

\subsection{Identification of functional groups}

The definition and analysis of functional groups followed the steps summarised in Fig. 2. Owing to the combination of qualitative and quantitative data and the use of many functional traits, a 'one step' classification for all functional traits was not deemed appropriate. Indeed, the similarity indices for combining qualitative and quantitative data tend to give greater weight to categorical rather than continuous variables, and processes that are related to any small subset of functional traits cannot be discriminated. For instance, a 'one step' classification could not identify the potential size selection of prey based on mouth size.

Individuals with similar combinations of functional traits were allocated to sub-functional groups that were assumed to reflect their ability to (A) swim, (B) approach their prey (detection, hunting strategies) in given prey habitats (bottom, water column) and (C) eat prey of similar types and size. Sub-functional groups were obtained using k-means (Hartigan \& Wong, 1979) with 25 sets of random centres. The optimal number of groups was assessed based on the silhouette width (a measure of the relative difference between within-group and between-group dissimilarity; Rousseeuw, 1987), with a minimum of three groups; the higher (closer to one) the silhouette width, the better the grouping. To use k-means with mixed data types (sub-function approach \& space use), additional steps were required before classification and a similarity matrix was built, using Gower's (1971) similarity index as modified by Podani (1999). This allows both ordinal and categorical data to be included. Metric properties were kept by calculating a distance matrix as $d=\sqrt{1-s}$ (Legendre \& Legendre, 1998, p 276), with $d$ the distance and $s$ the similarity. The distance matrix was then used for k-means classification.

The sub-functions were combined so that each group is a unique combination of the three subfunctional groups. Documented relationships between morphology and predation functions (reviewed in Sibbing \& Nagelkerke, 2001, see also Table I) were used to infer the sub-function and function (combined sub-functional groups) from functional traits values. Four potential prey characteristics, each with two or three levels (Table II), were related to combinations of sub functions. For instance, mobility of potential prey will depend on the predator swimming capacity and strategy to approach the prey (e.g. ambush predation). Predictions of potential prey characteristics for combined groups were of the form 'habitat-mobility-size-digestibility'. As prey mobility could not be expressed for all combined groups it was kept undefined in seven cases.

Several morphology types can serve the same ecological function: thus morphological groups as obtained by combination of sub-functions were 'predation strategy groups'. Different combinations of swimming capability and type of approach may notably provide a same ability to catch elusive prey (Table II). Hence, a given functional group may gather individuals with dissimilar morphologies which support different strategies to catch similar prey. Those predation strategy groups with matching ecological functions were therefore gathered to create functional groups. This means that, for instance, strategy groups predicted to be potential 'benthic-small-soft-preyconsumers' and 'benthic-elusive-small-soft-prey-consumers' ended up in different functional groups although some individuals of the former might feed on elusive prey. 


\subsection{Species and size-based predictions}

Since the functional traits might change with size, individuals of the same species but different sizes may be assigned to different functional groups. Also owing to within-species variability in morphology, individuals of the same size may end up in different groups. To estimate the probability of an individual of given species and size belonging to a given functional group, withinspecies size classes that were functionally homogeneous for each sub-function were identified. The proportions of different functional groups within these size classes were calculated. Proportions $<0.1$ were disregarded and the remaining rescaled (to sum to 1) and used as probabilities.

To check whether functional groups were size- and/or taxonomy-driven, (1) among functional group and (2) within functional group, inter-species differences in total length were tested using generalised linear models. Significantly different mean total lengths for functional groups indicate the effects of size on ecological functions, whereas size differences among species in the same functional group suggest similarity of function at different sizes.

\subsection{Relationships between functional groups and diet}

Since different predation strategy groups can fulfil the same predation function, relationships between diet and functional groups, rather than functional traits, were investigated.

Records of stomach contents from 5047 individual fishes, each of which fell within the size ranges of the corresponding species used for the functional classification were extracted from the dataset of Pinnegar et al. (2003). In total 8831 prey items were recorded in these stomachs. The probability that an individual of given species and size belonged to a given functional group was estimated following the method for species and size based prediction (see preceding section). As the numbers of smaller prey items (typically zooplankton or smaller) were not recorded in a consistent way in the dataset, prey numbers were set to one in stomachs of Argentina sphyraena L. 1758, Capros aper L. 1758, Clupea harengus L. 1758, Scomber scombrus L. 1758, Sprattus sprattus L. 1758 and Trachurus trachurus L. 1758. Three levels of prey identification were used (1) taxonomic group (algae, cephalopods, chaetognath, cnidarian, crustacean, echinoderm, fish, mollusc, polychaete, tunicate, phytoplankton and uncategorised), (2) expected prey role based on the prey characteristics used to define predator functions (Appendix A) and (3) habitat (benthic-ordemersal and pelagic). Information was scarce concerning prey length and many prey types were organisms that span a wide range of sizes throughout their life; hence, size was not explicitly taken into account when defining prey roles. As most stomachs contained few prey individuals and these would be linked to one or very few prey roles, contents of up to 20 stomachs were aggregated from predators of the same species and size class (i.e. with identical predicted predation function), to decrease variability in the estimated prey proportions. Two hundred and sixty-nine 'metaindividuals' were obtained this way and their diet assessed as the proportions of abundance of prey items. Fish diet-functional group relationships were investigated using Canonical Correspondence Analysis (CCA; Ter Braak, 1986) with the diet as dependent variable and probabilities of functional group membership as explanatory variables (adapted from de Merona et al., 2008). These analyses use $\chi^{2}$ distance and are therefore more reliable for data with many zeros, such as diet matrices, than the more widely used Euclidean distance (Legendre \& Legendre, 1998). Data rows were weighted by the sample size of prey individuals. The percentage of constrained variance was assessed from CCA and its significance tested using a Monte-Carlo routine ( $10^{5}$ simulations). CCAs were performed using R 2.14.2 ( $R$ Development Core Team, 2006) with the ade4 (version 1.4.17, http://pbil.univ- 
lyon1.fr/ade4/home.php?lang=eng; last accessed 22 March 2013) and made4 (version 1.4.0, http://www.bioconductor.org/packages/bioc/1.7/src/contrib/html/made4.html; last accessed 22 March 2013) packages.

The analyses were also repeated with individuals classified in size classes rather than functional groups (11 length classes of equal width on a log scale; to match the number of functional groups) to compare the proportion of diet variability explained by size to that explained by functional groups.

\section{Results}

\subsection{Identification and characterisation of functional groups}

Classification using k-means revealed three groups for each of the three sub-functions (optimal number according to silhouette index; Fig. 3). Individuals in group A1 'swimming capabilities \& metabolic rates', were characterised by high relative body depth and low caudal fin aspect ratios (Fig. 4.A), and are therefore expected to have a low capacity for sustained swimming and medium metabolic rates. Moreover, their laterally compressed body means they are "highly manoeuvrable individuals' but with high drag, making them adapted either for grazing or for burst swimming and chasing prey with high manoeuvrability over short distances. Those in group A2 were characterised by a fusiform body (low body width and depth relative to length) which confers low drag. They had a wide range of caudal fin aspect ratios, including high ratios. Fish in group A2 are adapted for strong acceleration (low aspect ratio) or for sustained swimming (large aspect ratio) and therefore should have medium to high metabolism ('burst or sustained swimmers'). Individuals from group A3 had the widest and more dorso-ventrally compressed bodies ('flatfishes') and had low caudal fin aspect ratios, thus low capacity for sustained swimming and relatively low metabolism. Conger eel Conger conger L. 1758 and Cuckoo ray Leucoraja naevus (Müller \& Henle 1841) were excluded from this classification because aspect ratio could not be calculated for species that lacked a defined caudal fin.

For the 'approach \& space use' sub-function, group B1 was characterised by the presence of barbels and absence of protrusive terminal mouth, with mouths sometimes pointing downward (Fig. 4.B). Fishes in this group are therefore expected to feed near the bottom (possibly on muddy bottoms) and to be 'fishes adapted to turbid conditions'. In group B2, short heads and protrusive mouths pointing downward, with small gape indicate individuals likely to catch preys directly on the bottom ('bottom feeders'). Group B3 included individuals with large heads, a protrusive terminal or upward pointing mouth and medium to large relative mouth opening ('suction, ram, pursuit or ambushed predators'). Except for ambush predators, most fish in B3 capture their prey in the lower part of the water column. In this classification, only individuals of group B1 were characterised by barbels and the discrimination between groups B2 and B3 was largely attributed to mouth orientation. This result shows the predominance of categorical and ordinal traits over continuous ones in the dissimilarity assessment.

For the potential 'prey size \& types' sub-function, group C1 included fish characterised by small gapes (limiting prey size) and relatively long digestive tracts (Fig. 4.C), making them potential consumers of 'small-hard-to-digest prey'. Individuals from group C2 were characterised by long guts and large mouth opening and potentially consume 'large-hard-prey'. Fishes in group C3 were characterised by short guts and small gapes and are therefore expected to feed on small easy to digest animal preys ('small-soft-prey consumers'). 
Size matters regardless of species for the 'prey size \& type' sub-function only (Fig. 5). Individuals of the 'large hard-prey consumers' group (C2) are generally larger than those of other groups. For this sub-function, differences of group membership driven by size also appeared within seven species (namely Zeus faber L. 1758, T. trachurus, Lophius piscatorius L. 1758, Lophius budegassa (Spinola 1807), Gadus morhua L. 1758, Hippoglossoides platessoides (Fabricius 1780) and Limanda limanda L. 1758; Fig. 6.b). The two other sub-functions, 'swimming capabilities \& metabolic rates' and 'type of approach \& space use', were driven only by species identity (Appendix B). The functional trait distributions for functionally homogeneous within-species sizeclasses are summarised in Table SI (online supporting material).

When groups from the three sub-functional classifications were combined, 14 predation strategy groups with data were identified out of 27 possible combinations (Appendix C). Based on known relationships between morphology and predation functions, different strategies can be used to feed on similar prey types (described in Table II). These strategies were identified and combined into 11 predation functional groups, called F1 to F11 (Appendix C). Size (total length) was significantly different among functional groups (GLM, gamma family, inverse link: $\chi^{2} \approx 359$, $d f=10, p \leq 2 \cdot 10^{-16}$ ). Potential omnivorous groups (F1 \& F2) included the smallest individuals, whereas for the other groups, no clear pattern appeared that would highlight any relationship between size and potential type of preys. For instance, soft-prey-consumers (groups F6 to F10, see Appendix C) spanned a wide range of sizes.

Two functional groups were mono-specific (F8 \& F9; Fig. 7), and both were defined by different size classes of $Z$. faber. All other groups were multi-specific and even included species belonging to different orders and/or families (listed in Table SI in online supporting material), e.g. group F1 included both Microchirus variegatus (Donovan 1808) (O. Pleuronectiformes) and small monkfish (Lophius spp, O. Lophiiformes). Within these multi-specific functional groups, different species often had different sizes (Fig. 7). Most within-species size classes were assigned to only one functional group, e.g. C. aper, Microstomus kitt (Walbaum 1792) or G. morhua (Fig. 7), while for other species (e.g. L. limanda, Melanogrammus aeglefinus L. 1758, C. maculatus or Trisopterus minutus L. 1758) individuals of the same size-class belonged to different functional groups, indicating within-species variability of morphology.

Seven species had a within species size effect (Fig. 7), owing to the persistence of within-species size effect for the sub-function 'prey size \& type' (Fig. 6).

\subsection{Predaction function versus diet}

According to CCA, all diet composition matrices were significantly related to the functional classification $\left(p<10^{-5}\right)$. Prey habitat was best predicted by functional groups, followed by prey category and taxonomic group (Table III). In all cases, functional groups better explained diet than size groups (12\% to $24 \%$ of explained variance versus $28 \%$ to $56 \%$ for functional groups). Functional groups with the lowest correlation with diet were those that were the least well represented in the stomach content data base.

Most potential soft-prey consumers (groups F7-F10) consumed teleost fish as shown by concomitant correlations of functional groups with CCA components and loadings of prey items (Fig. 8.a \& d). Those adapted to feed on 'benthic-low-mobility-small-hard-prey' (group F4) and in a lesser extent 'benthic-elusive-small-soft-prey' (group F11), fed on polychaetes and molluscs (Fig. 8.a) which were mainly bivalves and gasteropods (Fig. 8.d) and a low proportion of 
cephalopods for individuals able to feed on elusive prey (F11; Fig. 8.b). Individuals in group F3 (omnivorous, adapted to benthic, large prey) were characterised by high consumption of crabs and flatfish (Fig. 8.c). Group F5 (adapted to eat 'benthic-elusive-small-hard prey') fed on echinoderms (urchins and ophiurids/starfish) and more surprisingly on algae (Fig. 8.b \& d), deemed to be amongst the hardest to digest food items. They also consumed, in lower proportions, small crustaceans (shrimp, zooplankton, euphosids/mysids/amphipods; Fig. 8.d). 'Hard-prey consumers' in group F6 consumed zooplankton (Fig. 8.c) and some polychaetes (Fig. 8.b), but were more omnivorous than expected since they also consumed phytoplankton (Fig. 8.a \& c). Unsurprisingly, potential omnivores in groups F1 and F2 were not well characterised by particular prey types.

\section{Discussion}

Eleven predator functional groups were defined; they were based on both predator species and size and significantly explained diet composition. Size effects were revealed by size differences among groups and ontogenic changes in group membership, while taxonomic effects were revealed because several species were assigned to only one functional group despite spanning a wide range of body sizes, and by significant size differences between species within several groups. The within-species size effect reflects the size effect found in the predation sub-function 'prey size \& type'. Such a result was attributable to the use of a two-level classification and could not have been obtained with a taxonomic approach without knowledge of the predation functions at different life stages of each species. The effect of taxonomy is also suggested by the grouping of only flatfishes in functional group F10. The co-occurrence of intra-specific size-effects and specieseffects within size-structured groups is consistent with the findings of Jennings et al. (2002). These authors showed that in the North Sea demersal community (not only fishes), trophic level, in part an outcome of the predation function, was positively correlated with body size at both community and species levels but, at a given trophic level, different species had different sizes.

These results must be considered in the context of the debate about the relative contributions of size and phylogeny to ecological functions. There are evidences for both size (e.g. Petchey et al., 2008) and phylogenetic (e.g. Rezende et al., 2009; Stouffer et al., 2012) influences on trophic functions, though it remains an open question which is the main driver (Naisbit et al., 2012), It is however most likely that contributions are both noticeable and intricate (Jennings et al., 2002; Naisbit et al., 2012). The aim of this study was not to contribute to this a debate but to propose a method to categorise individuals, taking into account both influences. Nevertheless, the results demonstrate that taking into account size-driven intra-specific variations in functional traits (allometries) leads to a size-and-species-driven classification which better explains predation function than size only. Whether it better explains diet than a solely phylogenetic classification was not examined.

Most functional groups included individuals that were either omnivorous or adapted to feed on small and hard to digest prey whereas only a small proportion of groups were adapted to feed on medium or large and easy to digest animals (groups F3, F9, F8, at the highest trophic levels). Moreover, functional groups at low trophic levels generally included more species than those at the highest trophic levels (the mono-specific groups are only medium/large soft-prey consumers). Mono-specificity in some functional groups (medium \& large $Z$. faber) may indicate a key-species (i.e. the collapse of the species means the collapse of its associated function, Walker, 1992), but it could also result from incomplete sampling of the community since not all species are well caught by the sampling gear or might be rare. 
Diet composition was better explained by functional groups than by size groups. Moreover, the predictions of prey type based on morphology were consistent with observed diet characteristics, including prey digestibility, size (despite limited information in the stomach content data) and habitat (based on the analysis of functional traits related to space use and hunting strategies). However, in some functional groups, unexpected types of prey were found. Potential 'hard-preyconsumers' of groups F5 consumed algae and those of group F6 exhibited a high consumption of phytoplankton, although they were expected to prefer animal material. Such unexpected diets could pertain to prey characteristics - for instance, some types of phytoplankton such as diatoms might be easier to digest than expected (Cleveland \& Montgomery, 2003). Predators might also have developed specific adaptations - e.g. individuals of group F6, and some species of group F5, had well developed stomachs shaped as pockets which could improve the residence time of prey and hence the capacity of the individuals to digest them. Day et al. (2011) also showed that enzymatic adaptations and efficient pre-processing of food by jaw apparatus may provide an efficient way to process plant material in stomachless and short-gut fishes.

In contrast with our results, Motta et al. (1995) found morphology to be a poor predictor of diet, although they used a similar set of functional traits (including individual size). One difference was the absence of gut length in their trait selection. Ibañez et al. (2007) and this study show relative gut length to be one of the functional traits which explain a large proportion of variance in diet. The functional trait selection is however not deemed to be the only possible cause for a weak dietmorphology relationship. Indeed, other studies that accounted for gut length amongst a set of relevant functional traits, for example Albouy et al. (2011), found morphology to be a poor predictor of diet. The identification of different strategies for a similar predation function allows the identification of morphologically distant individuals with similar functions (e.g. M. variegatus and small Lophius spp). The existence of such strategies could in part explain the weak morphologydiet relationships found by Motta et al. (1995) and Albouy et al. (2011). Similarly, taking into account ontogenic changes in predation function might also partly explain the better dietmorphology relationship evidenced in this study compared to Albouy et al. (2011), who characterised the relationship at the species level.

In accordance with studies on the George Bank fish community using a trophic guild approach (Garrison \& Link, 2000b) and on a Mediterranean lagoon fish community using an ecomorphological approach (Dumay et al., 2004), fishes belonging to different families were shown to have similar ecological functions. This suggests at least partial redundancy in ecological functions, supported by taxonomically distant fish taxa, and is the sign of evolutionary convergence toward similar functions. This also corroborates the findings of Ibañez et al. (2007) who found no effect of phylogenetic distance on several functional traits related to diet, and even showed a significant positive autocorrelation of gut length with phylogenetic distance, suggesting convergence again.

Some limitations of the present methods can be identified. The use of categorical variables in the calculation of a similarity matrix based on the Gower's index as modified by Podani (1999) may have undesirable effects on the functional group definition. Since similarity between different levels is null, categorical variables tend to create higher contrasts than continuous variables. The problem is comparable for ordinal data with few levels. This is illustrated by the discrimination of individuals according to 'approach \& space use', which is determined by the presence/absence of barbels (categorical) and by mouth orientation (ordinal) among individuals without barbels, while quantitative variables do not influence the discrimination. For the two other classifications, only based on continuous data, the contributions of functional traits were more balanced (except for the undiscriminating wet weight). Size effects in predation processes, which are generally described by continuous variables (e.g. mouth size) could therefore be reduced by the use of ordinal or categorical data. Categorical functional traits could however help to enhance the resolution of the 
classification on 'prey size \& type'. For instance, teeth types might help to improve the classification concerning the type of prey a predator could handle, but may in turn reduce the information on size selection contributed by mouth size (continuous). Nevertheless, attenuations of the information borne by a given functional trait, as caused by such numerical behaviour and/or by the use of a large set of traits in an one-way classification, are limited by using combinations of several classification on fewer traits. The latter approach even led to more subtle discriminations, as shown, for instance, by the distinction of predation strategy groups with different relative gut length (soft-prey-consumers of group F9 to omnivores of group F3; Appendix C), all originating from sub-function $\mathrm{C} 2$ which exhibited a wide range of values for this trait (Fig. 4.C).

The fact that over $50 \%$ of diet variance was not constrained by the classification could arise from variability in diet, limitations in diet classification, limitations of ecomorphology or context specific changes (in terms of prey availability, prey switching, habitat mediated behaviour, etc.) in predatorprey relationships. Indeed, individual predation ability (i.e. potential function) is not the only factor influencing the range of prey caught. Prey availability and interactions with other predators are also expected to constrain diet (realised niche, Norton et al., 1995; Motta et al., 1995). The classification itself is a simplification of the diversity in potential predation roles, i.e. the lower the number of groups, the higher the expected intra-group diet variability. Further, assessment of diet may be biased by differences in the digestion time of different prey types and therefore in the capacity to identify them. Known limitations of ecomorphological approaches are (Norton, 1995; Sibbing \& Nagelkerke, 2001): (1) behavioural plasticity of predators, notably in response to competition or varying predation and (2) the confounding effects of evolutionary processes and structural constraints altering the morphology-function relationship (e.g. shapes may be more similar within than among families as a consequence of a common evolutionary history, also called 'phylogenetic artifact' by Douglas \& Matthews, 1992; see also de Merona et al., 2008). The first limitation might raise the need for observation and characterisation of behavioural plasticity across sizes and species to enhance the understanding of such variations in morphology-function relationships. The latter is not likely to be prevalent here, since the groups defined in the present study gathered taxonomically distant individuals, some with dissimilar morphologies (different strategies) while discriminating individuals taxonomically related (some of the same species). Phylogenetic artifacts should therefore be negligible.

The developed method helps to define predation functional groups for a broad range of predators based on techniques that are less expensive and time consuming than stomach sampling. Moreover, this method does not require complete knowledge of predation functions by size-andspecies based entities - knowledge of documented relationships between morphology and functions is sufficient. This is particularly advantageous for communities with a large diversity of potential predator species and sizes. Given that the traits used are expected to be relatively constant over ecological time, and depend on size and species identity, the groups can be used to categorize individuals and species in food webs for the purposes of analysis and modeling in a reliable and easy way.

Acknowledgements: We wish to thank our colleagues involved in the EVHOE ground-fish survey in 2006 for their help in sampling. The research was supported by the European Network of Excellence EUR-OCEANS (PhD project WP4-SYSNS-1093). We thank D Mouillot and four anonymous referees for helpful comments on previous versions of the manuscript. Many thank also to A Brind'amour for her invaluable advices about multivariate methods. 
Albouy, C., Guilhaumon, F., Villéger, S., Mouchet, M., Mercier, L., Culioli, J. M., Tomasini, J., Le Loc'h, F. \& Mouillot, D. (2011) Predicting trophic guild and diet overlap from functional traits: statistics, opportunities and limitations for marine ecology. Marine Ecology Progress Series 436, 17-28. doi:10.3354/meps09240

Auster, P. J. \& Link, J. S. (2009) Compensation and recovery of feeding guilds in a northwest Atlantic shelf fish community. Marine Ecology Progress Series 382, 163172. doi: $10.3354 /$ meps 07962

Bacha, M. \& Amara, R. (2009) Spatial, temporal and ontogenetic variation in diet of anchovy (Engraulis encrasicolus) on the Algerian coast (SW Mediterranean). Estuarine Coastal And Shelf Science 85, 257-264. doi:10.1016/j.ecss.2009.08.009

Binning, S. A. \& Chapman, L. J. (2010) Is intraspecific variation in diet and morphology related to environmental gradients? Exploring Liem's paradox in a cichlid fish. Integrative Zoology 5, 241-255. doi:10.1111/j.1749-4877.2010.00209.x

Boyle, K. S. \& Horn, M. H. (2006) Comparison of feeding guild structure and ecomorphology of intertidal fish assemblages from central California and central Chile. Marine Ecology Progress Series 319, 65-84. doi:10.3354/meps319065

Carroll, A. M., Wainwright, P. C., Huskey, S. H., Collar, D. C. \& Turingan, R. G. (2004) Morphology predicts suction feeding performance in centrarchid fishes. Journal of Experimental Biology 207, 3873-3881. doi:10.1242/jeb.01227

Cleveland, A. \& Montgomery, W. L. (2003) Gut characteristics and assimilation efficiencies in two species of herbivorous damselfishes (Pomacentridae : Stegastes dorsopunicans and S. planifrons). Marine Biology 142, 35-44. doi:10.1007/s00227002-0916-4

Day, R. D., German, D. P., Manjakasy, J. M., Farr, I., Hansen, M. J. \& Tibbetts, I. R. (2011) Enzymatic digestion in stomachless fishes: how a simple gut accommodates both herbivory and carnivory. Journal of Comparative Physiology B; Biochemical Systemic and Environmental Physiology 181, 603-613. doi:10.1007/s00360-0100546-y

de Merona, B., Hugueny, B., Tejerina-Garro, F. L. \& Gautheret, E. (2008) Diet-morphology relationship in a fish assemblage from a medium-sized river of French Guiana: the effect of species taxonomic proximity. Aquatic Living Resources 21, 171-184. doi:10.1051/alr:2008032

De Roos, A., Persson, L. \& McCauley, E. (2003) The influence of size-dependent lifehistory traits on the structure and dynamics of populations and communities. Ecology Letters 6, 473-487. doi:10.1046/j.1461-0248.2003.00458.x

Douglas, M. E. \& Matthews, W. J. (1992) Does morphology predict ecology? Hypothesis testing within a freshwater stream fish assemblage. Oikos 65, 213-224. doi: $10.2307 / 3545012$

Dumay, O., Tari, P., Tomasini, J. \& Mouillot, D. (2004) Functional groups of lagoon fish species in Languedoc Roussillon, southern France. Journal of Fish Biology 64, 970983. doi:10.1111/j.1095-8649.2004.00365.x

Garrison, L. P. \& Link, J. S. (2000a) Fishing effects on spatial distribution and trophic guild structure of the fish community in the Georges Bank region. ICES Journal of Marine Science 57, 723-730. doi:10.1006/jmsc.2000.0713 
Garrison, L. P. \& Link, J. S. (2000b) Dietary guilds structure of the fish community in the Northeast United States continental shelf ecosystem. Marine Ecology Progress Series 202, 231-240. doi:10.3354/meps202231

Gower, J. C. (1971) A general coefficient of similarity and some of its properties. Biometrics 27, 857-871.

Hartigan, J. A. \& Wong, M. A. (1979) A K-means clustering algorithm. Applied Statistics 28, 100-108.

Heath, M. R. (2005) Changes in the structure and function of the North Sea fish foodweb, 1973-2000, and the impacts of fishing and climate. ICES Journal of Marine Science 62, 847-868. doi:10.1016/j.icesjms.2005.01.023

Hjelm, J., Svanback, R., Bystrom, P., Persson, L. \& Wahlstrom, E. (2001) Diet-dependent body morphology and ontogenetic reaction norms in Eurasian perch. Oikos 95, 311323. doi:10.1034/j.1600-0706.2001.950213.x

Hjelm, J., van de Weerd, G. H. \& Sibbing, F. A. (2003) Functional link between foraging performance, functional morphology, and diet shift in roach (Rutilus rutilus). Canadian Journal of Fisheries and Aquatic Sciences 60, 700-709. doi:10.1139/F03058

Ibañez, C., Tedesco, P. A., Bigorne, R., Hugueny, B., Pouilly, M., Zepita, C., Zubieta, J. \& Oberdorff, T. (2007) Dietary-morphological relationships in fish assemblages of small forested streams in the Bolivian Amazon. Aquatic Living Resources 20, 131-142. doi:10.1051/alr:2007024

Inoue, T., Suda, Y. \& Sano, M. (2005) Food habits of fishes in the surf zone of a sandy beach at Sanrimatsubara, Fukuoka Prefecture, Japan. Ichthyological Research 52, 9-14. doi:10.1007/s10228-004-0246-2

Jax, K. (2005) Function and "functioning" in ecology: what does it mean? Oikos 111, 641648. doi:10.1111/j.1600-0706.2005.13851.x

Jennings, S., Pinnegar, J. K., Polunin, N. V. C. \& Warr, K. J. (2002) Linking size-based and trophic analyses of benthic community structure. Marine Ecology Progress Series 226, 77-85. doi:10.3354/meps226077

Karachle, P. K. \& Stergiou, K. I. (2010) Intestine morphometrics of fishes: a compilation and analysis of bibliographic data. Acta Ichthyologica et Piscatoria 40, 45-54. doi:10.3750/AIP2010.40.1.06

Labropoulou, M. \& Eleftheriou, A. (1997) The foraging ecology of two pairs of congeneric demersal fish species: importance of morphological characteristics in prey selection. Journal of Fish Biology 50, 324-340. doi:10.1111/j.1095-8649.1997.tb01361.x

Legendre, P. \& Legendre, L. (1998) Numerical Ecology. 2nd English edition. Amsterdam: Elsevier.

Lima-Junior, S. E. \& Goitein, R. (2003) Ontogenetic diet shifts of a neotropical catfish, Pimelodus maculatus (Siluriformes, Pimelodidae): An ecomorphological approach. Environmental Biology of Fishes 68, 73-79. doi:10.1023/A:1026079011647

Luczkovich, J. J., Norton, S. F. \& Gilmore, G. R. J. (1995) The influence of oral anatomy on prey selection during the ontogeny of two percoid fishes, Lagodon rhomboides and Centropomus undecimalis. Environmental Biology of Fishes 44, 79-95. doi:10.1007/BF00005908

Mackinson, S., Daskalov, G., Heymans, J. J., Neira, S., Arancibia, H., Zetina-Rejon, M., Jiang, H., Cheng, H. Q., Coll, M., Arreguin-Sanchez, F., Keeble, K. \& Shannon, L. (2009) Which forcing factors fit? Using ecosystem models to investigate the relative influence of fishing and changes in primary productivity on the dynamics of marine 
$\begin{array}{llll}\text { ecosystems. } & \text { Ecological } & \text { 220 } & \end{array}$ doi:10.1016/j.ecolmodel.2008.10.021

Motta, P. J., Clifton, K. B., Hernandez, P. \& Eggold, B. T. (1995) Ecomorphological correlates in ten species of subtropical seagrass fishes diet and microhabitat utilization. Environmental Biology of Fishes 44, 37-60. doi:10.1007/BF00005906

Mouillot, D., Spatharis, S., Reizopoulou, S., Laugier, T., Sabetta, L., Basset, A. \& Do Chi, T. (2006) Alternatives to taxonomic-based approaches to assess changes in transitional water communities. Aquatic Conservation: Marine and Freshwater ecosystems 16, 469-482. doi:10.1002/aqc.769

Naeem, S. \& Wright, J. P. (2003) Disentangling biodiversity effects on ecosystem functioning: deriving solutions to a seemingly insurmountable problem. Ecology Letters 6, 567-579. doi:10.1046/j.1461-0248.2003.00471.x

Naisbit, R. E., Rohr, R. P., Rossberg, A. G., Kehrli, P. \& Bersier, L. F. (2012) Phylogeny versus body size as determinants of food web structure. Proceedings of the Royal Society B-Biological Sciences 279, 3291-3297. doi:10.1098/rspb.2012.0327

Norton, S. F. (1995) A functional approach to ecomorphological patterns of feeding in cottid fishes. Environmental Biology of Fishes 44, 61-78. doi:10.1007/BF00005907

Norton, S. F., Luczkovich, J. J. \& Motta, P. J. (1995) The role of ecomorphological studies in the comparative biology of fishes. Environmental Biology of Fishes 44, 287-304. doi:10.1007/BF00005921

Palomares, M. L. D. \& Pauly, D. (1989) A multiple-regression model for predicting the food-consumption of marine fish populations. Australian Journal of Marine and Freshwater Research 40, 259-273. doi:10.1071/MF9890259

Palomares, M. L. D. \& Pauly, D. (1998) Predicting food consumption of fish populations as functions of mortality, food type, morphometrics, temperature and salinity. Marine and Freshwater Research 49, 447-453. doi:10.1071/MF98015

Persson, L., Andersson, J., Wahlstrom, E. \& Eklov, P. (1996) Size-specific interactions in lake systems: Predator gape limitation and prey growth rate and mortality. Ecology 77, 900-911. doi:10.2307/2265510

Petchey, O. L., Beckerman, A. P., Riede, J. O. \& Warren, P. H. (2008) Size, foraging, and food web structure. Proceedings Of The National Academy Of Sciences Of The United States Of America 105, 4191-4196. doi:10.1073/pnas.0710672105

Piet, G. J. (1998) Ecomorphology of a size-structured tropical freshwater fish community. Environmental Biology of Fishes 51, 67-86. doi:10.1023/A:1007338532482

Piet, G. J., Pfisterer, A. B. \& Rijnsdorp, A. D. (1998) On factors structuring the flatfish assemblage in the southern North Sea. Journal of Sea Research 40, 143-152. doi:10.1016/S1385-1101(98)00008-2

Pinnegar, J. K., Trenkel, V. M., Tidd, A. N., Dawson, W. \& Du buit, M. (2003) Does diet in Celtic Sea fishes reflect prey availability? Journal of Fish Biology 63, 197-212. doi:10.1046/j.1095-8649.2003.00204.x

Podani, J. (1999) Extending Gower's general coefficient of similarity to ordinal characters. Taxon 48, 331-340. doi:10.2307/1224438

R Development Core Team (2006) R: A Language and Environment for Statistical Computing. http://www.R-project.org

Rasband, W. S. (1997-2007) ImageJ. http://rsb.info.nih.gov/ij/

Rezende, E. L., Albert, E. M., Fortuna, M. A. \& Bascompte, J. (2009) Compartments in a marine food web associated with phylogeny, body mass, and habitat structure. Ecology Letters 12, 779-788. doi:10.1111/j.1461-0248.2009.01327.x 
Rousseeuw, P. J. (1987) Silhouettes: A graphical aid to the interpretation and validation of cluster analysis. Journal of Computational and Applied Mathematics 20, 53-65. doi:10.1016/0377-0427(87)90125-7

Scharf, F. S., Juanes, F. \& Rountree, R. A. (2000) Predator size-prey size relationships of marine fish predators: interspecific variation and effects of ontogeny and body size on trophic-niche breadth. Marine Ecology Progress Series 208, 229-248. doi:10.3354/meps208229

Shin, Y., Rochet, M., Jennings, S., Field, J. \& Gislason, H. (2005) Using size-based indicators to evaluate the ecosystem effects of fishing. ICES Journal of Marine Science 62, 384-396. doi:10.1016/j.icesjms.2005.01.004

Sibbing, F. A. \& Nagelkerke, L. A. J. (2001) Resource partitioning by Lake Tana barbs predicted from fish morphometrics and prey characteristics. Reviews in Fish Biology and Fisheries 10, 393-437. doi:10.1006/jfbi.2001.1580

Stouffer, D. B., Sales-Pardo, M., Sirer, M. I. \& Bascompte, J. (2012) Evolutionary Conservation of Species' Roles in Food Webs. Science 335, 1489-1492. doi:10.1126/science.1216556

Svanbäck, R. \& Eklöv, P. (2004) Morphology in perch affects habitat specific feeding efficiency. Functional Ecology 18, 503-510. doi:10.1111/j.0269-8463.2004.00858.x

Ter Braak, C. J. F. (1986) Canonical Correspondence Analysis: a new eigenvector technique for multivariate direct gradient analysis. Ecology 67, 1167-1179.

Trenkel, V. M., Pinnegar, J. K., Dawson, W. A., du Buit, M. H. \& Tidd, A. N. (2005) Spatial and temporal structure of predator-prey relationships in the Celtic Sea fish community. Marine Ecology Progress Series 299, 257-268. doi:10.3354/meps299257

Trenkel, V. M., Pinnegar, J. K., Rochet, M. \& Rackham, B. D. (2004) Different surveys provide similar pictures of trends in a marine fish community but not of individual fish populations. ICES Journal of Marine Science 61, 351-362. doi:10.1016/j.icesjms.2004.01.004

Villéger, S., Miranda, J. R., Hernandez, D. F. \& Mouillot, D. (2010) Contrasting changes in taxonomic vs. functional diversity of tropical fish communities after habitat degradation. Ecological Applications 20, 1512-1522. doi:10.1890/09-1310.1

Walker, B. H. (1992) Biodiversity and ecological redundancy. Conservation Biology 6, 1823. doi:10.1046/j.1523-1739.1992.610018.x

Ward-Campbell, B. M. S., Beamish, F. W. H. \& Kongchaiya, C. (2005) Morphological characteristics in relation to diet in five coexisting Thai fish species. Journal of Fish Biology 67, 1266-1279. doi:10.1111/j.1095-8649.2005.00821.x

Xie, S., Cui, Y. \& Li, Z. (2001) Dietary-morphological relationships of fishes in Liangzi Lake, China. Journal of Fish Biology 58, 1714-1729. doi:10.1111/j.10958649.2001.tb02325.x 
Table 1. List of functional traits recorded. The first column indicates to which predation subfunctions these functional traits are related. References report relationships between morphological traits and predation functions. The measurements needed to apply formulae are shown in Fig. 1, except $M_{W}$ : wet mass (nearest $0.1 \mathrm{~g}$, precision balance); $L_{G}$ : gut length from beginning of oesophagus to the anus (nearest $\mathrm{mm}$, flexible ruler); $\mathrm{B}$ : presence/absence of barbels and $\mathrm{O}$ : mouth orientation (ordinal categories: ventral $=1$, ventral/terminal $=2$, terminal $=3$, terminal $/$ dorsal $=4$, dorsal $=5$ ).

\section{Predation sub-function Functional trait (unit) Formula definition}

References

\begin{tabular}{|c|c|c|c|}
\hline \multirow{2}{*}{ Prey size \& type } & mean mouth diameter $(\mathrm{mm})$ & $\left(\mathrm{H}_{\mathrm{M}}+\mathrm{W}_{\mathrm{M}}\right) / 2^{(*)}$ & $1,2,3$ \\
\hline & relative gut length & $\mathrm{L}_{\mathrm{G}} / \mathrm{L}_{\mathrm{S}}$ & $4,5,6$ \\
\hline \multirow{4}{*}{ Swimming capacity \& } & individual weight (g) & $\mathrm{M}_{\mathrm{W}}$ & $7,8,9,10$ \\
\hline & relative body depth & $\mathrm{D}_{\mathrm{B}} / \mathrm{L}_{\mathrm{S}}$ & $3,11,12$ \\
\hline & relative body width & $\mathrm{W}_{\mathrm{B}} / \mathrm{L}_{\mathrm{S}}$ & 13,14 \\
\hline & caudal fin aspect ratio & $\mathrm{S}_{\mathrm{C}}^{2} / \mathrm{A}_{\mathrm{C}}$ & $7,9,15$ \\
\hline \multirow{5}{*}{ Type of approach \& } & relative head length & $\mathrm{L}_{\mathrm{HC}} / \mathrm{L}_{\mathrm{S}}$ & 14 \\
\hline & relative protrusion length & $\left(\mathrm{L}_{\mathrm{HO}}-\mathrm{L}_{\mathrm{HC}}\right) / \mathrm{L}_{\mathrm{HC}}$ & $8,9,10,14$ \\
\hline & relative mouth opening & $\left(2 \pi \mathrm{H}_{\mathrm{M}} / 2 \cdot \mathrm{W}_{\mathrm{M}} / 2\right) /\left(2 \pi \mathrm{D}_{\mathrm{B}} / 2 \cdot \mathrm{W}_{\mathrm{B}} / 2\right)^{(*)}$ & $9,10,14$ \\
\hline & presence/absence of barbels & B & 1 \\
\hline & orientation of opened mouth & $\mathrm{O}$ & 14,16 \\
\hline
\end{tabular}

References: 1: Piet, 1998; 2: Scharf et al., 2000; 3: Hjelm et al., 2003; 4: Xie et al., 2001; 5: Boyle \& Horn, 2006; 6: Karachle \& Stergiou, 2010; 7: Palomares \& Pauly, 1989; 8: Dumay et al., 2004; 9: Villéger et al., 2010; 10: Albouy et al., 2011; 11: Hjelm et al., 2001; 12: Svanbäck \& Eklöv, 2004; 13: Piet et al., 1998; 14: Sibbing \& Nagelkerke, 2001; 15: Palomares \& Pauly, 1998; 16: WardCampbell et al., 2005. 
Table 2. Potential prey characteristics used to gather predation strategy groups into predation functional groups. Related predation sub-functions of predators (A: swimming capacity; B: type of approach; C: prey size and type) link prey characteristics to diet predictions for sub-functional groups.

\begin{tabular}{llll}
\hline Prey & Predation & levels (description) & term in predation \\
characteristic & sub-function & & description \\
\hline & & bottom (prey found on or in the bottom) & benthic \\
\cline { 3 - 4 } prey habitat & $\mathrm{B}$ & water-column (prey near the bottom or pelagic) & water-column \\
& & & \\
\hline
\end{tabular}

\begin{tabular}{|c|c|c|c|}
\hline \multirow[t]{2}{*}{ prey mobility } & \multirow[t]{2}{*}{ A, B } & $\begin{array}{l}\text { low (prey which cannot escape by swimming - low } \\
\text { mobility compared to most fishes) }\end{array}$ & low-mobility \\
\hline & & medium/high (prey able to escape by swimming) & elusive \\
\hline \multirow{4}{*}{ prey size } & \multirow{4}{*}{$\mathrm{C}$} & small (required predator mouth diameter $\leq 30 \mathrm{~mm}$ ) & small \\
\hline & & medium $(30 \mathrm{~mm}<$ predator mouth & \multirow[b]{2}{*}{ medium } \\
\hline & & diameter $\leq 70 \mathrm{~mm})$ & \\
\hline & & large (predator mouth diameter $>70 \mathrm{~mm}$ ) & large \\
\hline \multirow{4}{*}{$\begin{array}{l}\text { prey } \\
\text { digestibility }\end{array}$} & \multirow{4}{*}{$\mathrm{C}$} & difficult (plants, detritus,...) & omnivorous \\
\hline & & medium (animals with protection e.g. thick skin, hard & hard-prey-consumer \\
\hline & & exoskeleton, shells,...) & \\
\hline & & $\begin{array}{l}\text { easy (animals with no or weak protection e.g. thin- } \\
\text { skinned fish, worms, shrimp,...) }\end{array}$ & soft-prey-consumer \\
\hline
\end{tabular}


Table 3. Percent of diet variance explained by CCA using size-and-species-driven functional groups versus size-only groups, for different diet characteristics.

Diet characteristics (proportions) size-and-species groups size groups

\begin{tabular}{lcc}
\hline taxonomic groups & $27.5 \%$ & $12.3 \%$ \\
& & \\
prey-function-based categories ${ }^{(1)}$ & $42.4 \%$ & $23.5 \%$ \\
prey habitat & $55.5 \%$ & $18.8 \%$ \\
\hline
\end{tabular}

(1) see Table III. 
Fig. 1. Measurements performed on individual fish. a) Fish with closed mouth: $L_{s}$ : standard length, $\mathrm{L}_{\mathrm{T}}$ : total length; $\mathrm{L}_{\mathrm{HC}}$ : head length; $\mathrm{D}_{\mathrm{B}}$ : maximum body depth; $\mathrm{W}_{\mathrm{B}}$ : maximum body width (all in $\mathrm{mm}$ ); both $S_{C}$ : caudal fin span (pixels) and $A_{C}$ : caudal fin area (pixels ${ }^{2}$ ) were assessed using image processing. b) Fish with fully opened mouth: $\mathrm{H}_{\mathrm{M}}$ : mouth height, $\mathrm{W}_{\mathrm{M}}$ : mouth width $\& \mathrm{~L}_{\mathrm{HO}}$ : head length (all in $\mathrm{mm}$ ). c) Frontal view, fully opened mouth: $\mathrm{W}_{\mathrm{B}}$ : body width; $\mathrm{W}_{\mathrm{M}}$ : mouth width (both in $\mathrm{mm}$ ). LT \& LS were measured using a fish measuring board (nearest $\mathrm{mm}$ ), the other measurements with a digital calliper (nearest $0.1 \mathrm{~mm}$ ) up to $150 \mathrm{~mm}$, with a divider and a ruler (nearest $\mathrm{mm}$ ) beyond.

Fig. 2. Main stages of the analysis, their data inputs and outputs.

Fig. 3. Silhouette width calculated for three to 15 groups obtained by k-means for sub-functions 'swimming capabilities \& metabolic rates' (A), 'type of approach \& space use' (B) and 'prey size \& type' (C). A higher index indicates a higher average degree of confidence in grouping (Rousseeuw, 1987).

Fig. 4. Distribution of functional trait values by group for A) 'swimming capabilities \& metabolic rates' sub-function. Group A1: high manoeuvrability; A2: burst or sustained swimming; A3: flatfishes. B) 'type of approach \& space use' sub-function. Mouth orientation: V: ventral; T/V: terminal/ventrally oriented; T: terminal; D/T: dorsally oriented/terminal. Group B1: Fishes adapted to turbid conditions; B2: Bottom feeders; B3: Suction, ram, pursuit or ambushed predators. C) 'prey size \& type' sub-function. Group C1: small-hard-prey consumers; C2: large-hard-prey consumers; C3: small-soft-prey consumers. Thick vertical bar: medians; Boxes: interquartile ranges; the whiskers extend to the data point at $\leq 1.5$ times the box length away from the box; values outside this range are represented by points. Box widths are proportional to the squareroots of group size.

Fig. 5. Distribution of individual size by group, for the three sub-functional classifications. Identification of groups as in Fig. 4.A for 'swimming capacity \& metabolism' , Fig. 4.B for 'approach \& space use' and Fig. 4.C for 'prey size \& type'. See Fig. 4 for box description.

Fig. 6. Proportion of individuals assigned to each group by size class and species for the subfunction 'prey size \& type'. Only species with evidenced ontogenic shifts are represented. Number of individuals is shown on each size class. Proportions $<10 \%$ not shown.

Fig. 7. Size and species composition of predation functional groups. Number of individuals is given in brackets after each species' name. Circle area is proportional to the proportion of a size class assigned to each group. Within group between-species size differences (GLMs, family Gamma, inverse link): n.s.: non significant; ${ }^{*}: p<0.05 ;{ }^{* *}: p<10^{-3}$; N.R.: not relevant (mono-specific groups). Grey levels refer to different size groups within species.

Fig. 8. Results of Canonical Correspondence Analysis (CCA): correlations of predator groups (arrows within the unit circle and bold grey labels) with analyses component and prey items scores (explained variables; italics) for (a) and (b) taxonomic groups of prey and (c) and (d) prey-rolebased categories as explained variables. Functional groups are identified as in Appendix C; preyrole categories are defined in Appendix A. The percent of explained variance taken into account by axis is reported in brackets under axes labels. 


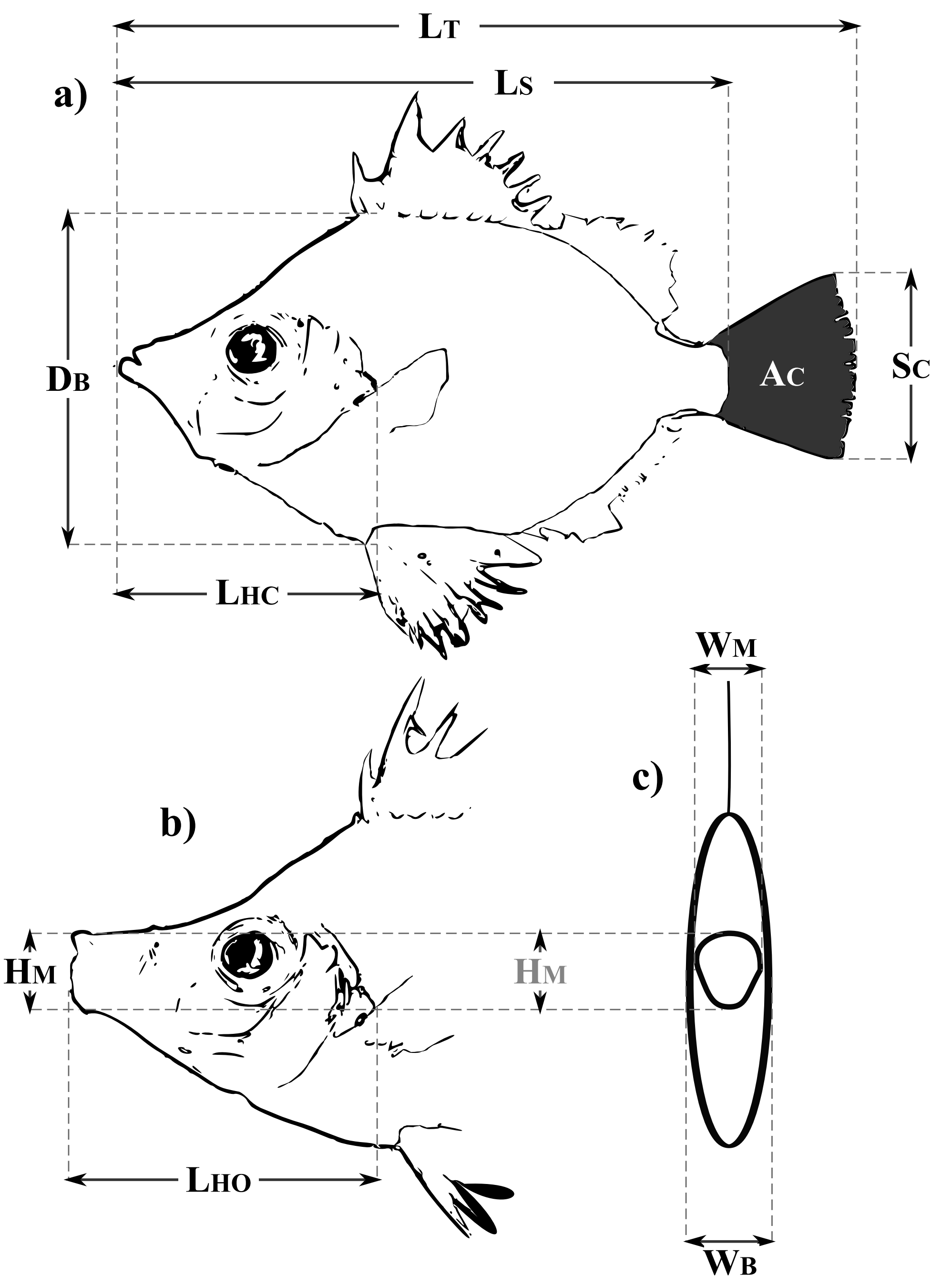




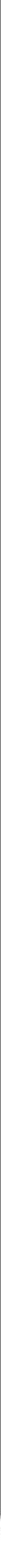




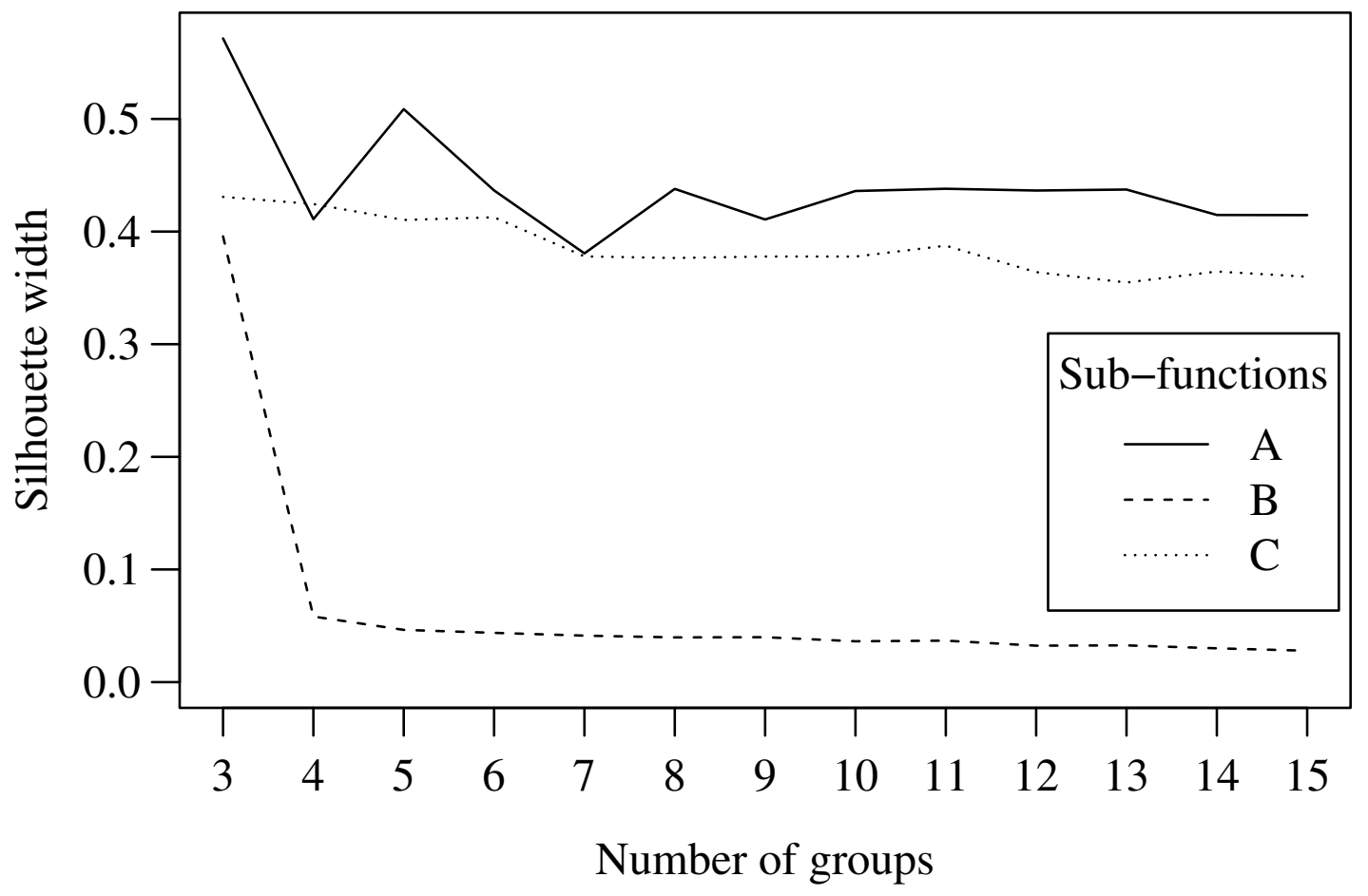




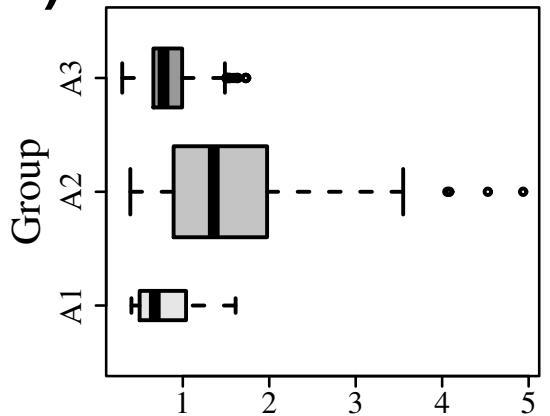

Caudal fin aspect ratio

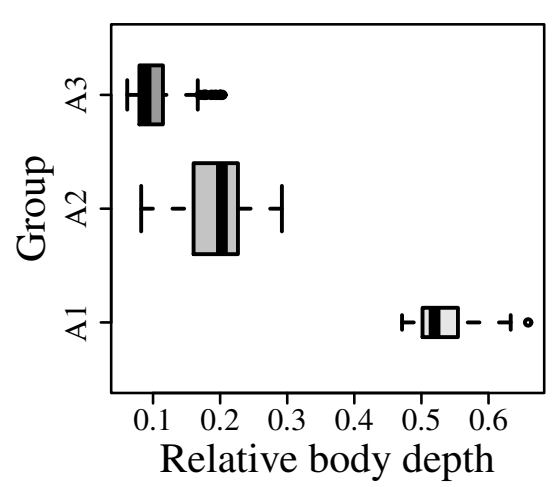

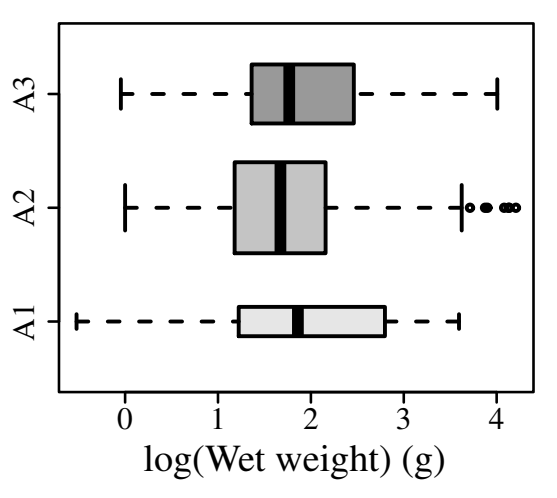

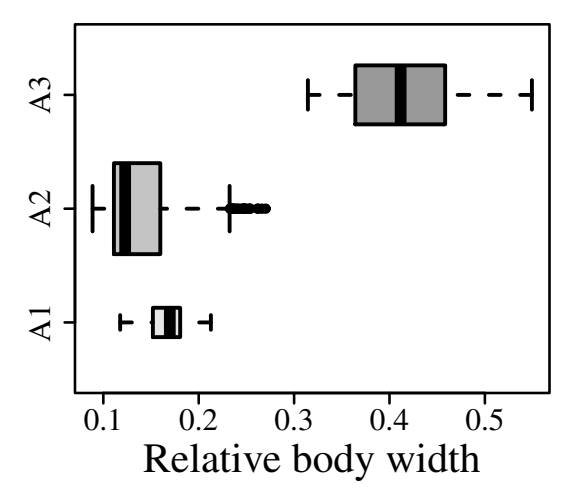

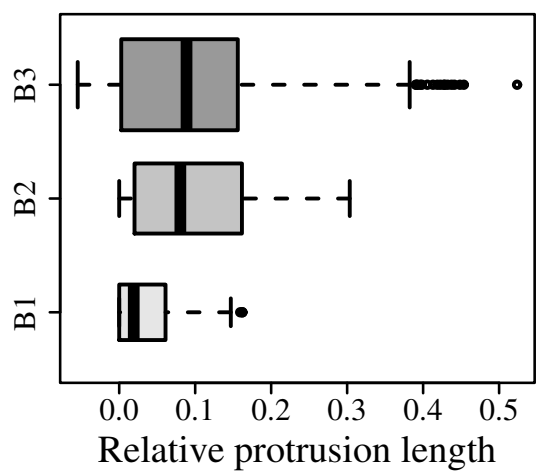

Mouth orientation
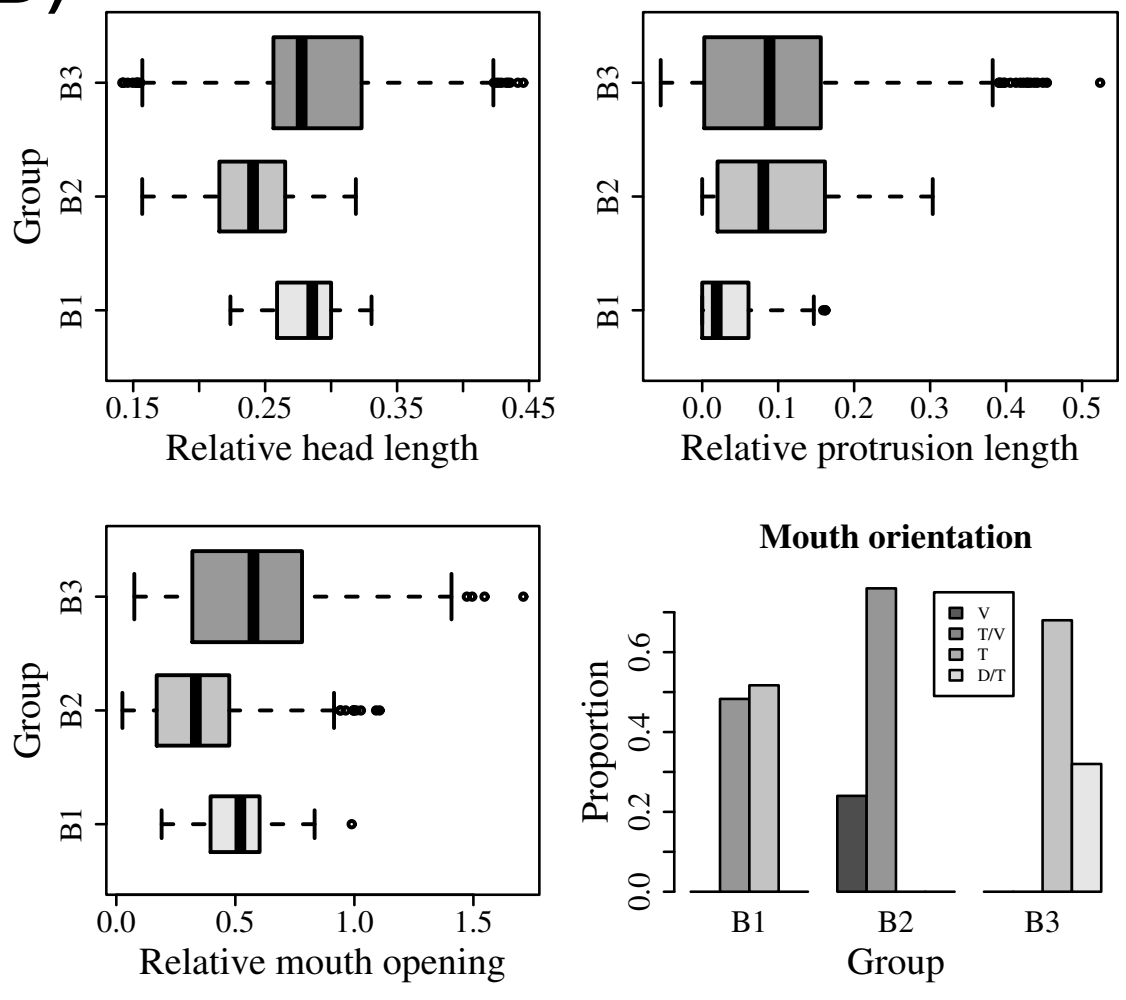

C)
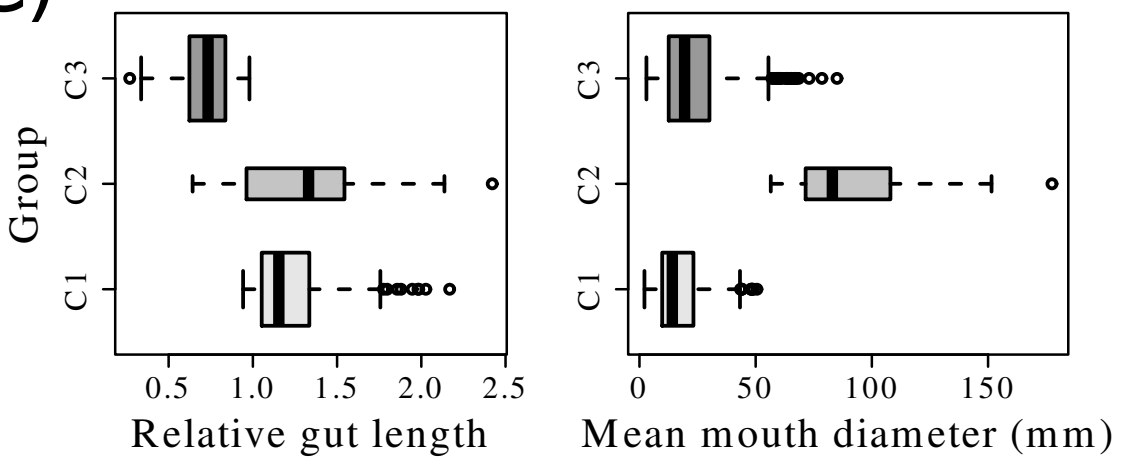

B) 
Swimming \& metabolism

Approach \& space use

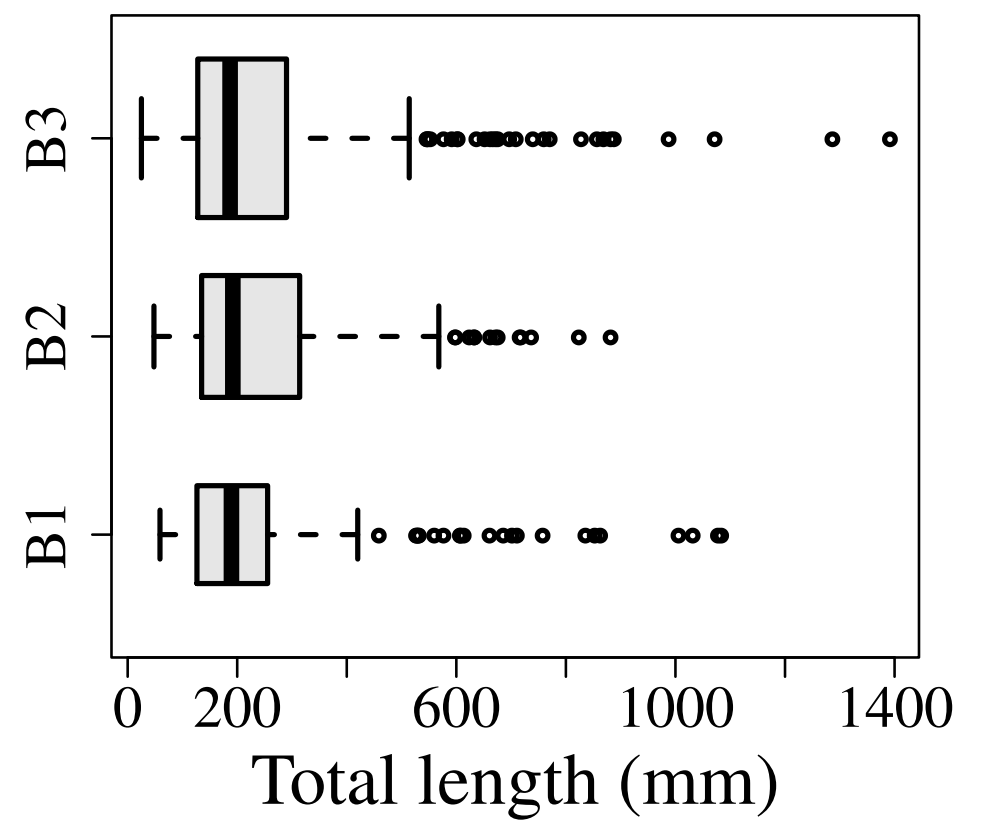

Prey size \& type

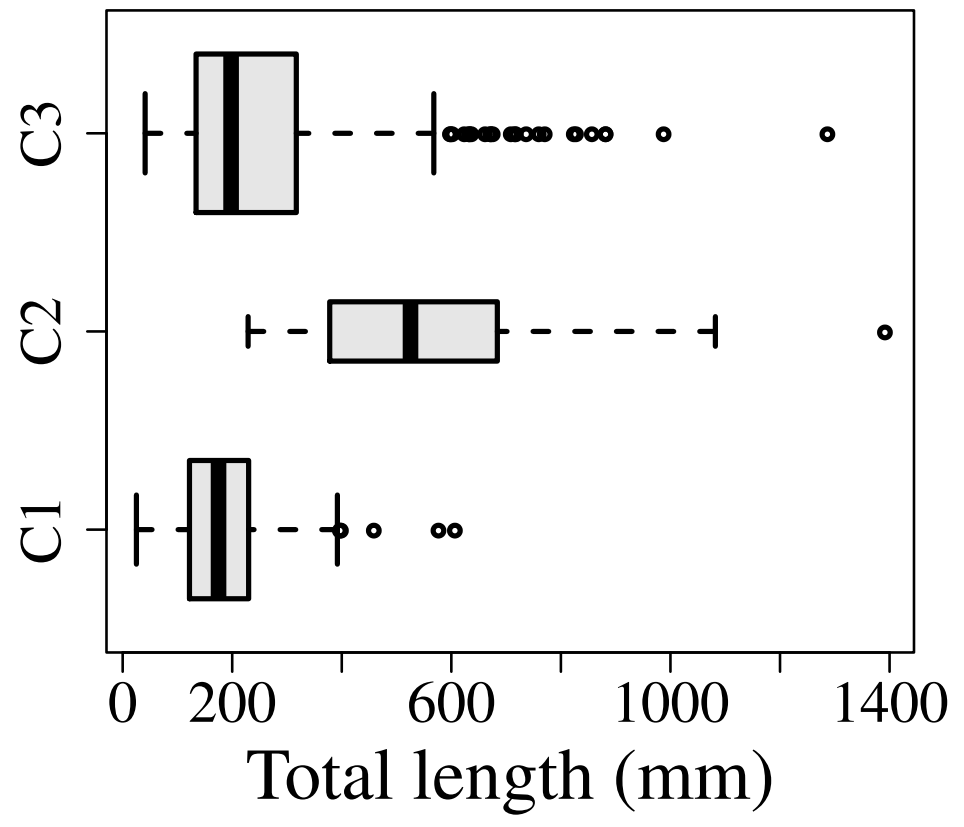


$\square \mathrm{C} 1$ - small-hard-prey consumers $\square \mathrm{C} 3$ - small-soft-prey consumers

$\boxminus \mathrm{C} 2$ - large-hard-prey consumers

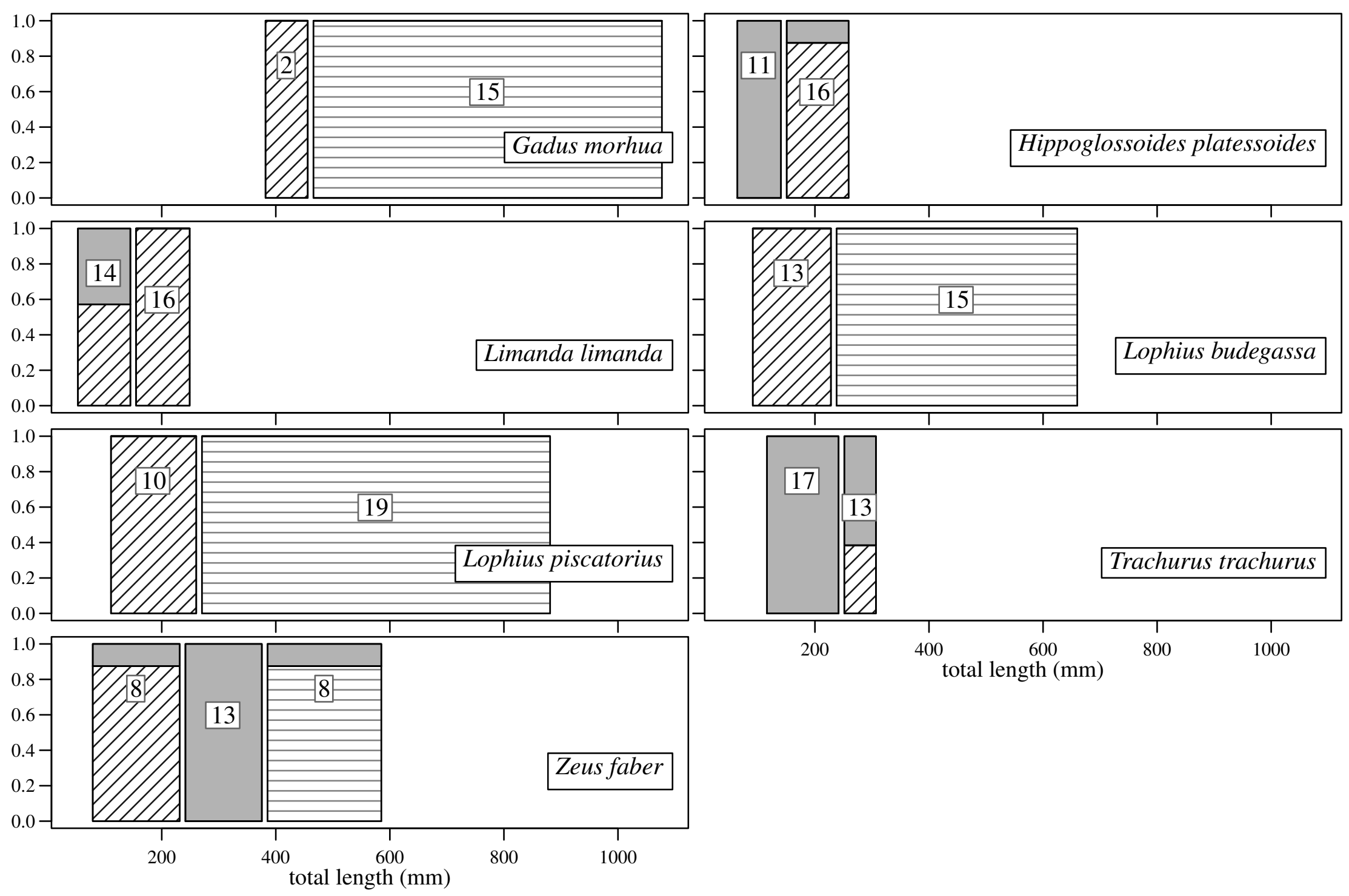


Functional group

$\begin{array}{llllllllllll}\text { F1 } & \text { F2 } & \text { F3 } & \text { F4 } & \text { F5 } & \text { F6 } & \text { F7 } & \text { F8 } & \text { F9 } & \text { F10 } & \text { F1 } 1\end{array}$

Microchirus variegatus (31)

Lophius piscatorius (29)

Lophius budegassa (27)

Capros aper (26)

Microstomus kitt (31)

Limanda limanda (30)

Callionymus maculatus (29)

Callionymus lyra (28)

Gadus morhua (17)

Chelidonichthys cuculus (33)

Eutrigla gurnardus (32) Melanogrammus aeglefinus (19)

Scomber scombrus (26)

Argentina silus (10)

Trachurus trachurus (29)

Sprattus sprattus (22)

Micromesistius poutassou (24)

Merlangius merlangus (30)

Merluccius merluccius (24)

Gadiculus argenteus (5)

Clupea harengus (29)

Argentina sphyraena (28)

Zeus faber (28)

Lepidorhombus whiffiagonis (25)

Hippoglossoides platessoides (26)

Arnoglossus imperialis (19)

Trisopterus esmarkii (27)

Squalus acanthias (8)

Scyliorhinus canicula (28)

Trisopterus minutus (32)

Molva molva (8)

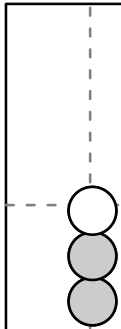

$\mathrm{O}$

0.2

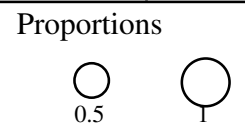

Proportions

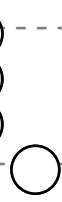

)

:

1
$\vdots$
$\ldots$$\ldots$

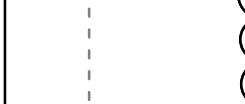

${ }^{-}$

1
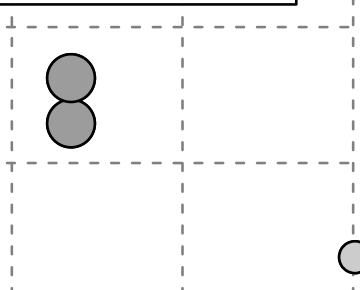

Within-species

size range $(\mathrm{mm})$

$\begin{array}{llllll}0 & 200 & 400 & 600 & 800 & 1000\end{array}$
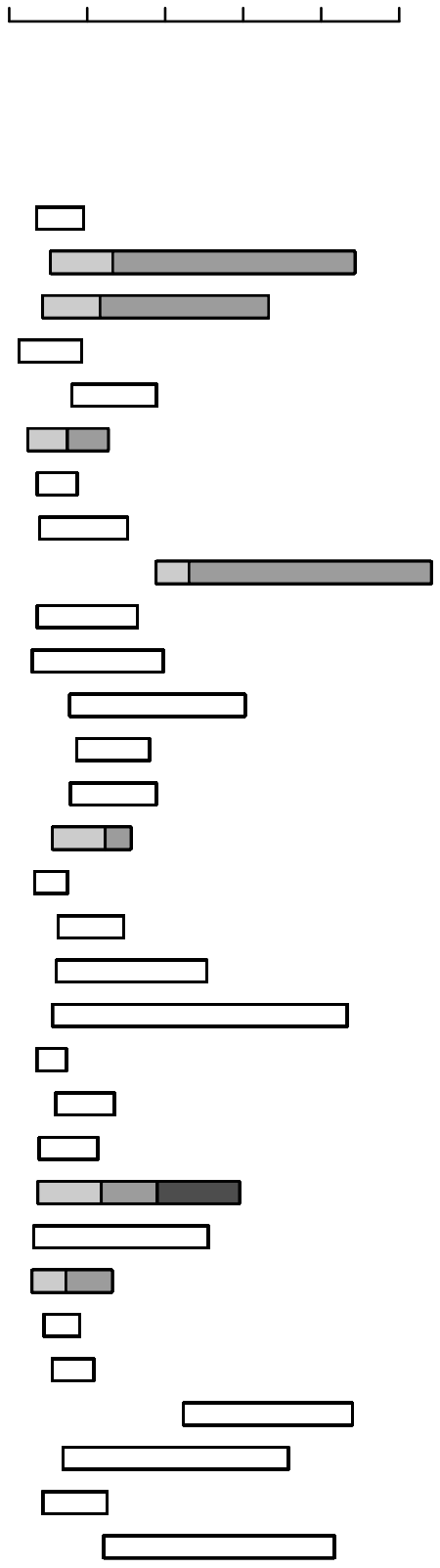

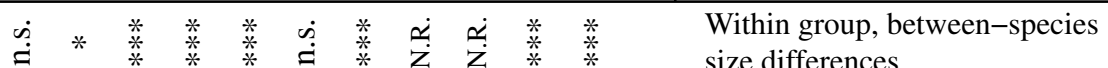
size differences 


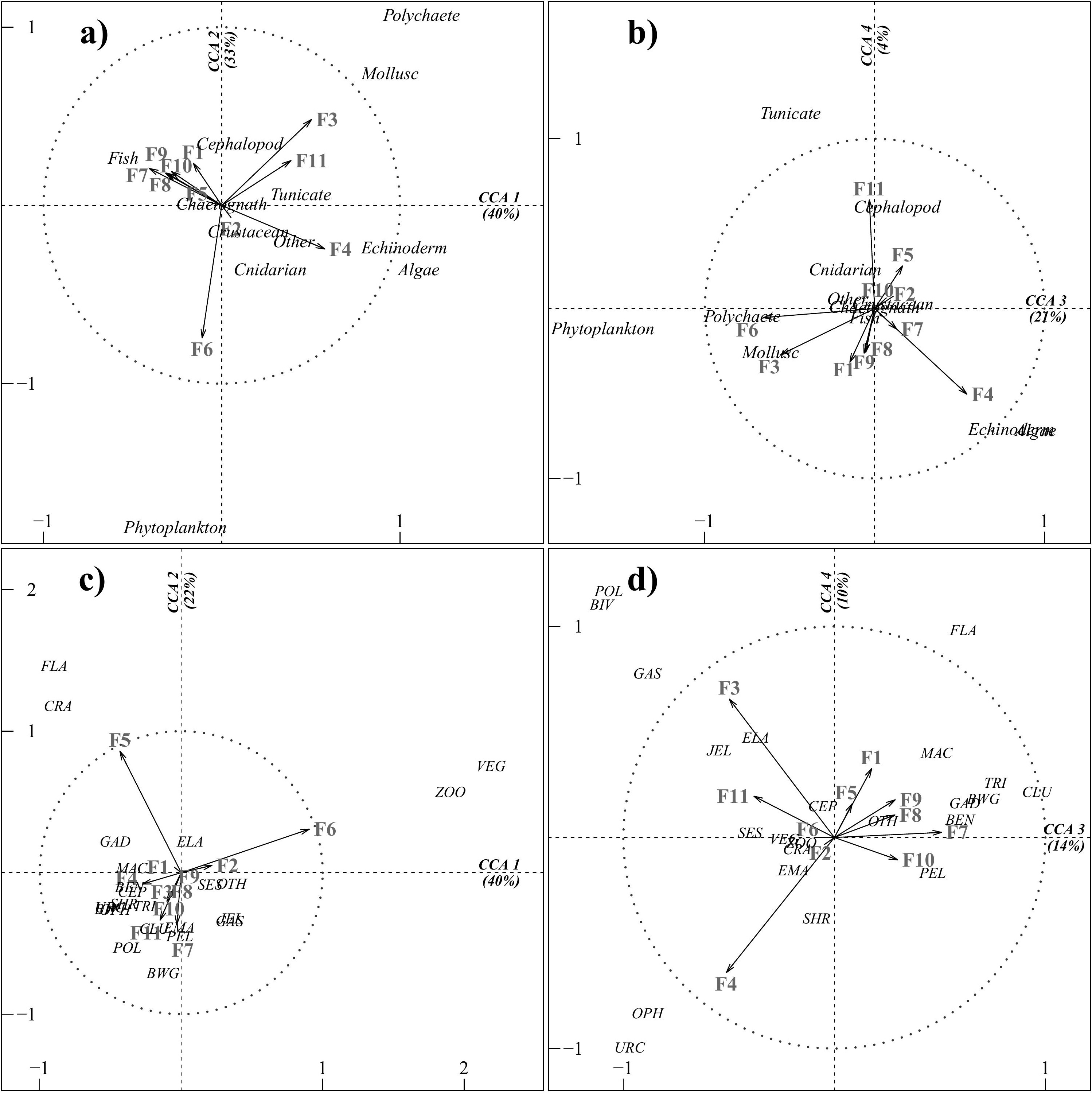




\section{APPENDIX A}

Prey categories based on taxonomic groups of prey split according to their expected habitat (benthic: B; water-column: W), digestibility (difficult: 1; medium: 2; easy: 3 ) and mobility (low: 0; elusive: 1) (see Table II). The absence of a characteristic indicates that variability within the taxonomic group precluded assigning a single characteristic.

\begin{tabular}{|c|c|c|c|c|}
\hline \multirow[t]{2}{*}{ Category } & \multirow[t]{2}{*}{ description } & \multicolumn{3}{|c|}{ Characteristics } \\
\hline & & habitat & digestibility & mobility \\
\hline CRA & Crabs \& lobsters & $\mathrm{B}$ & 2 & \\
\hline SHR & Shrimp + Nephrops spp & B & $2-3$ & \\
\hline EMA & Euphosids, Mysids, Amphipods, Isopods & & $2-3$ & \\
\hline $\mathrm{ZOO}$ & Copepods (zooplankton) & $\mathrm{W}$ & $2-3$ & \\
\hline GAS & Gasteropods & $\mathrm{B}$ & & 0 \\
\hline BIV & Bivalves & B & $1-2$ & 0 \\
\hline CEP & Cephalopods & & 3 & 1 \\
\hline POL & Polychaetes \& worms & & 3 & \\
\hline URC & Urchins + holoturians & B & $1-2$ & 0 \\
\hline $\mathrm{OPH}$ & Ophiurids \& starfish & $\mathrm{B}$ & $1-2$ & 0 \\
\hline SES & Sessile invertebrate & B & & 0 \\
\hline JEL & Jellyfish + sagita... & $\mathrm{W}$ & 3 & 0 \\
\hline CLU & Clupeoids (herring, sprat, anchovy) + Argentina spp & $\mathrm{W}$ & 3 & 1 \\
\hline TRI & Trisopterus $\mathrm{spp}+$ silvery pout & & 3 & 1 \\
\hline BWG & Blue whiting & $\mathrm{W}$ & 3 & 1 \\
\hline GAD & Other gadoids & & 3 & 1 \\
\hline FLA & Flatfishes & $\mathrm{B}$ & 3 & 1 \\
\hline BEN & Other benthic fishes & B & 3 & 1 \\
\hline MAC & Mackerel \& horse mackerel & $\mathrm{W}$ & 3 & 1 \\
\hline PEL & Other pelagic fishes & $\mathrm{W}$ & 3 & 1 \\
\hline ELA & Elasmobranchs & $\mathrm{B}^{1}$ & & 1 \\
\hline VEG & Phytoplankton & $\mathrm{W}$ & 1 & 0 \\
\hline OTH & Others: none categorised preys & & & \\
\hline
\end{tabular}

for species in the dataset. 


\section{APPENDIX B}

Species allocation, expressed as proportion of individuals, among groups within sub-function 'swimming capabilities \& metabolic rates' (A), 'type of approach \& space use' (B) and 'prey size \& types' $(C)$. Shadowed cells correspond to classifications not achieved because of functional traits not present for the species.

\begin{tabular}{|c|c|c|c|c|c|c|c|c|c|}
\hline \multirow[t]{2}{*}{ Sub-function } & \multicolumn{3}{|c|}{ A: Swimming } & \multicolumn{3}{|c|}{ B: Type of approach } & \multicolumn{3}{|c|}{ C: Prey type } \\
\hline & A1 & A2 & A3 & B1 & B2 & B3 & C1 & $\mathrm{C2}$ & C3 \\
\hline Capros aper & 1.00 & & & & & 1 & 0.96 & & 0.04 \\
\hline Zeus faber & 1.00 & & & & & 1 & 0.27 & 0.23 & 0.50 \\
\hline Chelidonichthys cuculus & & 1.00 & & 1 & & & 0.97 & & 0.03 \\
\hline Eutrigla gurnardus & & 1.00 & & 1 & & & 0.81 & & 0.19 \\
\hline Melanogrammus aeglefinus & & 1.00 & & 1 & & & 0.75 & & 0.25 \\
\hline Trisopterus minutus & & 1.00 & & 1 & & & 0.38 & & 0.62 \\
\hline Gadus morhua & & 1.00 & & 1 & & & 0.12 & 0.88 & \\
\hline Molva molva & & 1.00 & & 1 & & & 0.12 & 0.38 & 0.50 \\
\hline Trisopterus esmarkii & & 1.00 & & 1 & & & & & 1.00 \\
\hline Callionymus maculatus & & 1.00 & & & 1 & & 0.66 & & 0.34 \\
\hline Callionymus lyra & & 1.00 & & & 1 & & 0.64 & & 0.36 \\
\hline Squalus acanthias & & 1.00 & & & 1 & & & & 1.00 \\
\hline Scyliorhinus canicula & & 1.00 & & & 1 & & & & 1.00 \\
\hline Scomber scombrus & & 1.00 & & & & 1 & 0.97 & & 0.03 \\
\hline
\end{tabular}




\begin{tabular}{|c|c|c|c|c|c|c|c|c|c|}
\hline \multirow[t]{2}{*}{ Sub-function } & \multicolumn{3}{|c|}{ A: Swimming } & \multicolumn{3}{|c|}{ B: Type of approach } & \multicolumn{3}{|c|}{ C: Prey type } \\
\hline & A1 & A2 & A3 & B1 & B2 & B3 & C1 & $\mathrm{C} 2$ & C3 \\
\hline Argentina silus & & 1.00 & & & & 1 & 0.88 & & 0.12 \\
\hline Trachurus trachurus & & 1.00 & & & & 1 & 0.17 & & 0.83 \\
\hline Merlangius merlangus & & 1.00 & & & & 1 & 0.10 & & 0.90 \\
\hline Micromesistius poutassou & & 1.00 & & & & 1 & 0.08 & & 0.92 \\
\hline Argentina sphyraena & & 1.00 & & & & 1 & 0.06 & & 0.94 \\
\hline Merluccius merluccius & & 1.00 & & & & 1 & & 0.07 & 0.93 \\
\hline Sprattus sprattus & & 1.00 & & & & 1 & & & 1.00 \\
\hline Gadiculus argenteus & & 1.00 & & & & 1 & & & 1.00 \\
\hline Clupea harengus & & 1.00 & & & & 1 & & & 1.00 \\
\hline Lophius piscatorius & & 0.03 & 0.97 & & & 1 & 0.34 & 0.66 & \\
\hline Microstomus kitt & & & 1.00 & & 1 & & 0.97 & & 0.03 \\
\hline Limanda limanda & & & 1.00 & & 1 & & 0.80 & & 0.20 \\
\hline Hippoglossoides platessoides & & & 1.00 & & 1 & & 0.57 & & 0.43 \\
\hline Lepidorhombus whiffiagonis & & & 1.00 & & 1 & & & & 1.00 \\
\hline Arnoglossus imperialis & & & 1.00 & & 1 & & & & 1.00 \\
\hline Microchirus variegatus & & & 1.00 & & & 1 & 1.00 & & \\
\hline Lophius budegassa & & & 1.00 & & & 1 & 0.46 & 0.54 & \\
\hline Leucoraja naevus & & & & & 1 & & & & 1.00 \\
\hline Conger conger & & & & & & 1 & & 0.06 & 0.94 \\
\hline
\end{tabular}




\section{APPENDIX C}

Functional groups (FG) with their potential functional roles predicted from morphology. Body sizes in functional groups (Lt: total length) are expressed as mean \pm standard deviation. PSG: predation strategy groups. The codes for the combined groups are built as the group codes for respectively the sub-functions 'swimming capacity', 'type of approach' and 'prey type \& size', dot separated. For instance, an individual classified in groups A3, B2 and $\mathrm{C} 1$ of the corresponding sub-functions ends up in functional group F4 through strategy group A3.B2.C1.

\begin{tabular}{|c|c|c|c|c|}
\hline FG & Potential predation function & PSG & Characterisation/strategy & $\mathbf{L t}(\mathbf{m m})$ \\
\hline $\mathrm{F} 1$ & benthic-small-prey omnivorous & A3.B3.C1 & ambushed/suction & $142 \pm 39$ \\
\hline $\mathrm{F} 2$ & water-column-small-prey omnivorous & A1.B3.C1 & suction feeding, high manoeuvrability & $117 \pm 55$ \\
\hline \multirow{2}{*}{ F3 } & \multirow{2}{*}{ benthic-elusive-large prey omnivorous } & A2.B1.C2 & swimming hunter, adapted to turbidity & \multirow[t]{2}{*}{$557 \pm 226$} \\
\hline & & A3.B3.C2 & slow swimming, ambushed & \\
\hline \multirow{2}{*}{$\mathrm{F} 4$} & \multirow{2}{*}{$\begin{array}{l}\text { benthic-low-mobility-small-hard prey- } \\
\text { consumers }\end{array}$} & A2.B2.C1 & grazing & \multirow[t]{2}{*}{$190 \pm 72$} \\
\hline & & A3.B2.C1 & suction/grazing & \\
\hline F5 & $\begin{array}{l}\text { benthic-elusive-small-hard prey- } \\
\text { consumers }\end{array}$ & $\mathrm{A} 2 . \mathrm{B} 1 . \mathrm{C} 1$ & swimming hunter, adapted to turbidity & $201 \pm 101$ \\
\hline F6 & $\begin{array}{l}\text { water-column-small-hard prey- } \\
\text { consumers }\end{array}$ & $\mathrm{A} 2 . \mathrm{B} 3 . \mathrm{C} 1$ & cruising hunter & $239 \pm 65$ \\
\hline F7 & $\begin{array}{l}\text { water-column-small-soft prey- } \\
\text { consumers }\end{array}$ & A2.B3.C3 & swimming hunter & $208 \pm 110$ \\
\hline F8 & $\begin{array}{l}\text { water-column-medium-soft prey- } \\
\text { consumers }\end{array}$ & A1.B3.C3 & suction feeding, high manoeuvrability & $322 \pm 62$ \\
\hline F9 & $\begin{array}{l}\text { water-column-large-soft prey- } \\
\text { consumers }\end{array}$ & A1.B3.C2 & suction feeding, high manoeuvrability & $459 \pm 64$ \\
\hline F10 & benthic-small-soft prey-consumers & A3.B2.C3 & suction feeding & $212 \pm 135$ \\
\hline \multirow{2}{*}{ F11 } & \multirow{2}{*}{$\begin{array}{l}\text { benthic-elusive-small-soft prey- } \\
\text { consumers }\end{array}$} & A2.B1.C3 & ram feeding, adapted to turbidity & \multirow[t]{2}{*}{$263 \pm 184$} \\
\hline & & $\mathrm{A} 2 . \mathrm{B} 2 . \mathrm{C} 3$ & swimming hunter & \\
\hline
\end{tabular}




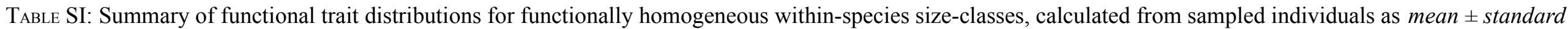

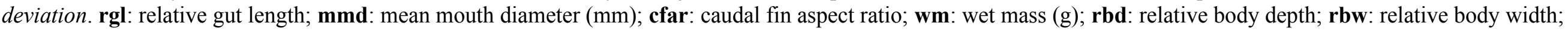

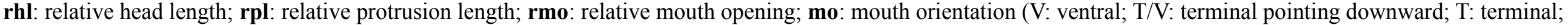
D/T: terminal, pointing upward); ba: presence/absence of barbels. See Table I for functional traits formulas.

Species are ordered by orders (O.; separated by thick lines) and families (F.). Species are individualised by alternate shading of rows.

\begin{tabular}{|c|c|c|c|c|c|c|c|c|c|c|c|c|}
\hline Common name Latin name & Size class $(\mathbf{m m})$ & rgl & mmd & cfar & $\mathbf{w m}$ & rbd & rbw & rhl & rpl & rmo & mo & ba \\
\hline O. Anguilliformes & F. Congridae & & & & & & & & & & & \\
\hline Conger eel Conger conger, $\mathrm{L}$. & {$[276,1390]$} & $0.49 \pm 0.13$ & $37.2 \pm 16.4$ & & $1372 \pm 2081$ & $0.07 \pm 0.01$ & $0.07 \pm 0.01$ & $0.15 \pm 0.01$ & $0.00 \pm 0.00$ & $0.49 \pm 0.15$ & $\mathrm{~T}$ & No \\
\hline O. Carcharhiniformes & F. Scyliorhinidac & & & & & & & & & & & \\
\hline Lesser-spotted dogfish Scyliorhinus canicula, L. & {$[138,716]$} & $0.62 \pm 0.04$ & $28.3 \pm 13.0$ & $1.43 \pm 0.18$ & $351 \pm 356$ & $0.10 \pm 0.01$ & $0.11 \pm 0.01$ & $0.17 \pm 0.01$ & $0.00 \pm 0.00$ & $0.48 \pm 0.08$ & $\mathrm{~V}$ & No \\
\hline O. Clupeiformes & F. Clupeidae & & & & & & & & & & & \\
\hline Herring Clupea harengus, L. & {$[119,270]$} & $0.73 \pm 0.04$ & $18.6 \pm 4.7$ & $2.3 \pm 0.40$ & $60 \pm 56$ & $0.23 \pm 0.01$ & $0.11 \pm 0.01$ & $0.25 \pm 0.01$ & $0.12 \pm 0.03$ & $0.57 \pm 0.11$ & $\mathrm{D} / \mathrm{T}$ & No \\
\hline Sprat Sprattus sprattus, L. & {$[65,150]$} & $0.68 \pm 0.05$ & $9.5 \pm 1.4$ & $1.80 \pm 0.30$ & $10 \pm 6$ & $0.24 \pm 0.02$ & $0.11 \pm 0.01$ & $0.25 \pm 0.02$ & $0.13 \pm 0.03$ & $0.41 \pm 0.11$ & $\mathrm{D} / \mathrm{T}$ & No \\
\hline O. Gadiformes & F. Gadidae & & & & & & & & & & & \\
\hline \multicolumn{8}{|l|}{ Blue whiting Micromesistius poutassou } & $0.27 \pm 0.01$ & $0.07 \pm 0.04$ & $0.85 \pm 0.11$ & $\mathrm{~T}$ & No \\
\hline \multirow[t]{2}{*}{ Cod Gadus morhua, L. } & {$[377,461[$} & $1.15 \pm 0.03$ & $40.2 \pm 5.3$ & $1.58 \pm 0.35$ & $582 \pm 88$ & $0.24 \pm 0.01$ & $0.15 \pm 0.01$ & $0.29 \pm 0.01$ & $0.00 \pm 0.00$ & $0.35 \pm 0.02$ & $\mathrm{~T}$ & Yes \\
\hline & {$[461,1082]$} & $1.44 \pm 0.19$ & $85.7 \pm 24.5$ & $1.62 \pm 0.20$ & $6202 \pm 5185$ & $0.25 \pm 0.02$ & $0.18 \pm 0.03$ & $0.30 \pm 0.01$ & $0.00 \pm 0.01$ & $0.35 \pm 0.06$ & $\mathrm{~T}$ & Yes \\
\hline Haddock Melanogrammus aeglefinus, L. & {$[155,605]$} & $1.11 \pm 0.22$ & $23.1 \pm 9.6$ & $1.43 \pm 0.27$ & $404 \pm 648$ & $0.23 \pm 0.01$ & $0.14 \pm 0.01$ & $0.29 \pm 0.01$ & $0.00 \pm 0.01$ & $0.26 \pm 0.04$ & $\mathrm{~T} / \mathrm{V}$ & Yes \\
\hline Norway-pout Trisopterus esmarkii (Nilsson 1855) & {$[110,217]$} & $0.71 \pm 0.11$ & $18.1 \pm 3.6$ & $0.87 \pm 0.16$ & $37 \pm 22$ & $0.22 \pm 0.01$ & $0.11 \pm 0.00$ & $0.26 \pm 0.01$ & $0.10 \pm 0.05$ & $0.59 \pm 0.06$ & $\mathrm{~T}$ & Yes \\
\hline Poor-cod Trisopterus minutus, L. & {$[86,251]$} & $0.93 \pm 0.11$ & $17.3 \pm 6.1$ & $1.01 \pm 0.22$ & $49 \pm 49$ & $0.25 \pm 0.02$ & $0.13 \pm 0.01$ & $0.26 \pm 0.01$ & $0.03 \pm 0.04$ & $0.48 \pm 0.07$ & $\mathrm{~T}$ & Yes \\
\hline \multicolumn{13}{|l|}{ Silvery-pout Gadiculus argenteus } \\
\hline (Guichenot 1850) & {$[71,94]$} & $0.56 \pm 0.06$ & $10.8 \pm 1.0$ & $0.8 \pm 0.10$ & $4 \pm 1$ & $0.21 \pm 0.01$ & $0.13 \pm 0.00$ & $0.30 \pm 0.01$ & $0.13 \pm 0.03$ & $0.81 \pm 0.10$ & $\mathrm{~T}$ & No \\
\hline \multirow[t]{2}{*}{ Whiting Merlangius merlangus, L. } & {$[124,507]$} & $0.85 \pm 0.12$ & $27.2 \pm 11.4$ & $1 \pm 0.29$ & $174 \pm 252$ & $0.21 \pm 0.02$ & $0.12 \pm 0.01$ & $0.28 \pm 0.01$ & $0.00 \pm 0.01$ & $0.65 \pm 0.10$ & $\mathrm{~T}$ & No \\
\hline & F. Lotidae & & & & & & & & & & & \\
\hline \multirow[t]{2}{*}{ Ling Molva molva, L. } & {$[242,834]$} & $1.02 \pm 0.14$ & $50.6 \pm 20.7$ & $1.22 \pm 0.18$ & $1151 \pm 1099$ & $0.13 \pm 0.01$ & $0.12 \pm 0.01$ & $0.23 \pm 0.00$ & $0.00 \pm 0.00$ & $0.63 \pm 0.09$ & $\mathrm{~T}$ & Yes \\
\hline & F. Merlucciidae & & & & & & & & & & & \\
\hline Hake Merluccius merluccius, L. & {$[111,867]$} & $0.59 \pm 0.14$ & $45.5 \pm 21.4$ & $0.81 \pm 0.22$ & $480 \pm 973$ & $0.17 \pm 0.02$ & $0.14 \pm 0.02$ & $0.29 \pm 0.01$ & $0.01 \pm 0.04$ & $0.98 \pm 0.25$ & $\mathrm{~T}$ & No \\
\hline O. Lophïformes & F. Lophiidae & & & & & & & & & & & \\
\hline Black-bellied angler & {$[86,233[$} & $1.43 \pm 0.18$ & $32.8 \pm 11.1$ & $0.70 \pm 0.20$ & $50 \pm 54$ & $0.14 \pm 0.02$ & $0.50 \pm 0.02$ & $0.39 \pm 0.02$ & $0.19 \pm 0.05$ & $1.21 \pm 0.23$ & $\mathrm{D} / \mathrm{T}$ & No \\
\hline Lophius budegassa (Spinola 1807) & {$[233,665]$} & $1.15 \pm 0.27$ & $78.4 \pm 22.8$ & $0.82 \pm 0.10$ & $962 \pm 1083$ & $0.15 \pm 0.02$ & $0.48 \pm 0.02$ & $0.35 \pm 0.01$ & $0.17 \pm 0.08$ & $0.91 \pm 0.20$ & $\mathrm{D} / \mathrm{T}$ & No \\
\hline \multirow[t]{2}{*}{ Angler Lophius piscatorius, L. } & {$[106,266[$} & $1.60 \pm 0.25$ & $37.7 \pm 8.9$ & $0.63 \pm 0.15$ & $71 \pm 55$ & $0.16 \pm 0.02$ & $0.49 \pm 0.02$ & $0.38 \pm 0.02$ & $0.23 \pm 0.04$ & $1.08 \pm 0.19$ & $\mathrm{D} / \mathrm{T}$ & No \\
\hline & {$[266,886]$} & $1.57 \pm 0.31$ & $107.8 \pm 29$ & $0.81 \pm 0.08$ & $2284 \pm 2311$ & $0.17 \pm 0.02$ & $0.46 \pm 0.05$ & $0.35 \pm 0.02$ & $0.19 \pm 0.07$ & $0.81 \pm 0.13$ & $\mathrm{D} / \mathrm{T}$ & No \\
\hline
\end{tabular}


TABLE SI continued

\begin{tabular}{|c|c|c|c|c|c|c|c|c|c|c|c|c|}
\hline Latin name & Size class $(\mathbf{m m})$ & rgl & mmd & cfar & wm & rbd & rbw & rhl & rpl & rmo & mo & ba \\
\hline O. Osmeriformes & F. Argentinidae & & & & & & & & & & & \\
\hline Greater-argentine Argentina silus (Ascanius 1775) & {$[165,377]$} & $1.06 \pm 0.08$ & $16.1 \pm 5.2$ & $2.42 \pm 0.20$ & $134 \pm 110$ & $0.18 \pm 0.01$ & $0.12 \pm 0.01$ & $0.25 \pm 0.01$ & $0.03 \pm 0.01$ & $0.24 \pm 0.03$ & $\mathrm{~T}$ & No \\
\hline Lesser-silver smelt Argentina sphyraena, L. & {$[77,227]$} & $0.81 \pm 0.08$ & $11.0 \pm 2.6$ & $2.23 \pm 0.47$ & $40 \pm 23$ & $0.17 \pm 0.01$ & $0.11 \pm 0.01$ & $0.26 \pm 0.01$ & $0.01 \pm 0.01$ & $0.28 \pm 0.05$ & $\mathrm{~T}$ & No \\
\hline O. Perciformes & F. Callionymidac & & & & & & & & & & & \\
\hline Dragonet Callionymus lyra, L. & {$[78,303]$} & $1.13 \pm 0.24$ & $16.7 \pm 10.1$ & $0.90 \pm 0.19$ & $55 \pm 53$ & $0.13 \pm 0.01$ & $0.24 \pm 0.01$ & $0.24 \pm 0.02$ & $0.07 \pm 0.04$ & $0.39 \pm 0.19$ & $\mathrm{~T} / \mathrm{V}$ & No \\
\hline \multicolumn{13}{|l|}{ Spotted-dragonet Callionymus maculatus } \\
\hline & F. Carangidae & & & & & & & & & & & \\
\hline \multirow[t]{3}{*}{ Horse-mackerel Trachurus trachurus, L. } & {$[111,247[$} & $0.77 \pm 0.10$ & $18.3 \pm 7.2$ & $2.57 \pm 0.36$ & $53 \pm 53$ & $0.23 \pm 0.01$ & $0.13 \pm 0.01$ & $0.28 \pm 0.01$ & $0.14 \pm 0.03$ & $0.55 \pm 0.06$ & $\mathrm{~T}$ & No \\
\hline & {$[247,312]$} & $0.92 \pm 0.12$ & $31.5 \pm 3.0$ & $2.82 \pm 0.28$ & $185 \pm 51$ & $0.22 \pm 0.01$ & $0.13 \pm 0.01$ & $0.29 \pm 0.01$ & $0.15 \pm 0.03$ & $0.57 \pm 0.05$ & $\mathrm{~T}$ & No \\
\hline & F. Scombridae & & & & & & & & & & & \\
\hline Mackerel Scomber scombrus, L. & {$[173,360]$} & $1.17 \pm 0.09$ & $25.0 \pm 5.4$ & $3.21 \pm 0.65$ & $127 \pm 116$ & $0.17 \pm 0.01$ & $0.12 \pm 0.01$ & $0.26 \pm 0.01$ & $0.04 \pm 0.03$ & $0.64 \pm 0.15$ & $\mathrm{~T}$ & No \\
\hline O. Pleuronectiformes & F. Bothidae & & & & & & & & & & & \\
\hline \multicolumn{13}{|l|}{ Imperial-scaldfish Arnoglossus imperialis } \\
\hline & F. Pleuronectida & & & & & & & & & & & \\
\hline \multirow[t]{2}{*}{ Dab Limanda limanda, L. } & {$[48,150[$} & $0.97 \pm 0.11$ & $7.3 \pm 2.2$ & $0.73 \pm 0.11$ & $15 \pm 10$ & $0.08 \pm 0.00$ & $0.43 \pm 0.01$ & $0.27 \pm 0.01$ & $0.11 \pm 0.02$ & $0.17 \pm 0.03$ & $\mathrm{~T} / \mathrm{V}$ & No \\
\hline & {$[150,254]$} & $1.11 \pm 0.10$ & $12.0 \pm 1.8$ & $0.87 \pm 0.20$ & $69 \pm 41$ & $0.09 \pm 0.01$ & $0.43 \pm 0.02$ & $0.26 \pm 0.01$ & $0.11 \pm 0.02$ & $0.15 \pm 0.03$ & $\mathrm{~T} / \mathrm{V}$ & No \\
\hline Lemon-sole Microstomus kitt (Walbaum 1792) & {$[161,378]$} & $1.16 \pm 0.17$ & $8.5 \pm 1.8$ & $1.42 \pm 0.21$ & $238 \pm 166$ & $0.10 \pm 0.01$ & $0.44 \pm 0.02$ & $0.19 \pm 0.01$ & $0.05 \pm 0.02$ & $0.04 \pm 0.01$ & $\mathrm{~T} / \mathrm{V}$ & No \\
\hline \multirow{3}{*}{$\begin{array}{l}\text { Long-rough dab Hippoglossoides platessoides } \\
\text { (Fabricius 1780) }\end{array}$} & {$[67,146[$} & $0.82 \pm 0.10$ & $9.6 \pm 3.0$ & $0.54 \pm 0.05$ & $7 \pm 6$ & $0.08 \pm 0.00$ & $0.33 \pm 0.02$ & $0.26 \pm 0.01$ & $0.19 \pm 0.03$ & $0.51 \pm 0.12$ & $\mathrm{~T} / \mathrm{V}$ & No \\
\hline & {$[146,264]$} & $1.05 \pm 0.15$ & $20 \pm 3.8$ & $0.78 \pm 0.17$ & $91 \pm 49$ & $0.08 \pm 0.00$ & $0.37 \pm 0.02$ & $0.24 \pm 0.01$ & $0.22 \pm 0.03$ & $0.40 \pm 0.06$ & $\mathrm{~T} / \mathrm{V}$ & No \\
\hline & F. Scophthalmid & & & & & & & & & & & \\
\hline \multicolumn{8}{|l|}{ Megrim Lepidorhombus whiffiagonis } & $0.30 \pm 0.01$ & $0.18 \pm 0.05$ & $0.87 \pm 0.13$ & $\mathrm{~T} / \mathrm{V}$ & No \\
\hline & F. Soleidae & & & & & & & & & & & \\
\hline $\begin{array}{l}\text { Thick-backed sole Microchirus variegatus } \\
\text { (Donovan 1808) }\end{array}$ & {$[70,191]$} & $1.40 \pm 0.21$ & $8.1 \pm 1.9$ & $0.69 \pm 0.13$ & $32 \pm 22$ & $0.09 \pm 0.00$ & $0.36 \pm 0.02$ & $0.22 \pm 0.01$ & $0.00 \pm 0.00$ & $0.15 \pm 0.02$ & $\mathrm{D} / \mathrm{T}$ & No \\
\hline O. Rajiformes & F. Rajidae & & & & & & & & & & & \\
\hline \multicolumn{13}{|l|}{ Cuckoo ray Leucoraja naevus } \\
\hline (Müller \& Henle 1841) & {$[172,660]$} & $0.46 \pm 0.03$ & $28.3 \pm 8.9$ & & $429 \pm 446$ & $0.06 \pm 0.01$ & $0.56 \pm 0.02$ & $0.27 \pm 0.01$ & $0.00 \pm 0.00$ & $0.16 \pm 0.03$ & $\mathrm{~V}$ & No \\
\hline
\end{tabular}


TABLE SI continued

\begin{tabular}{|c|c|c|c|c|c|c|c|c|c|c|c|c|}
\hline Latin name & Size class $(\mathbf{m m})$ & rgl & mmd & cfar & wm & rbd & rbw & rhl & rpl & rmo & mo & ba \\
\hline O. Scorpaeniformes & F. Triglidae & & & & & & & & & & & \\
\hline Grey-gurnard Eutrigla gurnardus, L. & {$[59,395]$} & $1.08 \pm 0.11$ & $20.3 \pm 6.7$ & $1.68 \pm 0.24$ & $74 \pm 117$ & $0.20 \pm 0.01$ & $0.17 \pm 0.01$ & $0.30 \pm 0.01$ & $0.03 \pm 0.02$ & $0.57 \pm 0.12$ & $\mathrm{~T} / \mathrm{V}$ & Yes \\
\hline Red-gurnard Chelidonichthys cuculus, L. & {$[72,329]$} & $1.20 \pm 0.15$ & $20.8 \pm 7.9$ & $1.49 \pm 0.41$ & $87 \pm 99$ & $0.21 \pm 0.01$ & $0.19 \pm 0.01$ & $0.30 \pm 0.01$ & $0.04 \pm 0.03$ & $0.57 \pm 0.15$ & $\mathrm{~T} / \mathrm{V}$ & Yes \\
\hline O. Squaliformes & F. Squalidae & & & & & & & & & & & \\
\hline Spurdog Squalus acanthias, L. & {$[446,880]$} & $0.67 \pm 0.04$ & $36.5 \pm 7.6$ & $2.01 \pm 0.17$ & $1313 \pm 961$ & $0.13 \pm 0.01$ & $0.12 \pm 0.00$ & $0.22 \pm 0.01$ & $0.00 \pm 0.00$ & $0.25 \pm 0.05$ & $\mathrm{~V}$ & No \\
\hline O.Zeiformes & F. Caproidae & & & & & & & & & & & \\
\hline \multirow[t]{2}{*}{ Boarfish Capros aper, L. } & {$[25.1,186]$} & $1.50 \pm 0.32$ & $9.5 \pm 4.3$ & $0.55 \pm 0.12$ & $32 \pm 30$ & $0.54 \pm 0.04$ & $0.18 \pm 0.01$ & $0.40 \pm 0.02$ & $0.30 \pm 0.10$ & $0.13 \pm 0.02$ & $\mathrm{~T}$ & No \\
\hline & F. Zeidae & & & & & & & & & & & \\
\hline \multirow[t]{3}{*}{ John-dory Zeus faber, L. } & {$[74,237[$} & $1.16 \pm 0.19$ & $28.2 \pm 13.1$ & $0.67 \pm 0.25$ & $94 \pm 90$ & $0.59 \pm 0.04$ & $0.14 \pm 0.02$ & $0.42 \pm 0.02$ & $0.36 \pm 0.03$ & $0.65 \pm 0.11$ & $\mathrm{~T}$ & No \\
\hline & {$[237,381[$} & $0.74 \pm 0.10$ & $60.5 \pm 9.3$ & $1.05 \pm 0.12$ & $589 \pm 215$ & $0.51 \pm 0.02$ & $0.16 \pm 0.03$ & $0.39 \pm 0.01$ & $0.33 \pm 0.08$ & $0.62 \pm 0.16$ & $\mathrm{~T}$ & No \\
\hline & {$[381,590]$} & $0.69 \pm 0.08$ & $88.8 \pm 14.0$ & $1.19 \pm 0.25$ & $1786 \pm 901$ & $0.50 \pm 0.02$ & $0.16 \pm 0.02$ & $0.39 \pm 0.01$ & $0.38 \pm 0.06$ & $0.68 \pm 0.06$ & $\mathrm{~T}$ & No \\
\hline
\end{tabular}

